\title{
Los límites de la humanidad. El mito de los ch'ullpa en Marcapata (Quispicanchi), Perú
}

Pablo F. Sendón

\section{OpenEdition}

1 Journals

Edición electrónica

URL: https://journals.openedition.org/jsa/11540

DOI: 10.4000/jsa. 11540

ISSN: 1957-7842

Editor

Société des américanistes

\section{Edición impresa}

Fecha de publicación: 5 diciembre 2010

Paginación: 133-179

ISSN: 0037-9174

\section{Referencia electrónica}

Pablo F. Sendón, «Los límites de la humanidad. El mito de los ch'ullpa en Marcapata (Quispicanchi), Perú», Journal de la Société des américanistes [En línea], 96-2 | 2010, Publicado el 10 diciembre 2014, consultado el 02 septiembre 2022. URL: http://journals.openedition.org/jsa/11540 ; DOI: https:// doi.org/10.4000/jsa. 11540 


\title{
LOS LÍMITES DE LA HUMANIDAD. EL MITO DE LOS CH'ULLPA EN MARCAPATA (QUISPICANCHI), PERÚ
}

\author{
Pablo F. SENDÓN *
}

En este artículo se presenta y discute el mito de los ch'ullpa - seres del tiempo presolar - tal y como es narrado por los miembros del ayllu Collana del distrito de Marcapata (provincia de Quispicanchi, Cusco) en relación con tres tipos de fuentes: a) la información arqueológica relativa a la ubicación geográfica y espacial de los monumentos funerarios que reciben dicho nombre en los Andes Centrales; b) la información etnológica relativa a otras versiones del mismo mito relevadas entre otras poblaciones campesino-indigenas del sur peruano y del altiplano boliviano; c) la información etnohistórica que, al respecto, ha sido recopilada por diversos especialistas. El objetivo principal del balance consiste en sentar las bases de una perspectiva comparativa del mito en cuestión con miras a trascender las especificidades de un estudio de caso concreto. [Palabras claves: ch'ullpa, monumentos funerarios, seres del tiempo pre-solar, mitología, sur peruano, Collasuyu.]

Les limites de l'humanité. Le mythe des ch'ullpa à Marcapata (Quispicanchi), Pérou. Cet article présente et discute le mythe des ch'ullpa (entités du temps pré-solaire) raconté par les membres de l'ayllu Collana du district de Marcapata (province de Quispicanchi, Cusco), à partir de trois types de sources: a) les données archéologiques sur la localisation géographique et spatiale des monuments funéraires qui portent ce nom dans les Andes centrales; b) les données ethnologiques portant sur d'autres versions du même mythe enregistrées parmi d'autres populations indigènes et paysannes du Sud péruvien et de l'Altiplano bolivien; c) les données ethnohistoriques compilées à ce sujet par différents spécialistes. L'objectif principal de ce bilan est de poser les bases d'une perspective comparative sur ce mythe et de dépasser les spécificités d'un cas ethnographique particulier. [Mots-clés: ch'ullpa, monuments funéraires, entités du temps présolaire, mythologie, sud du Pérou, Collasuyu.]

The limits of humanity. The myth of the ch'ullpa in Marcapata (Quispicanchi), Peru. This paper presents and discusses the myth of the ch'ullpa-beings of the pre-solar

* CONICET, Ayacucho $1553^{\circ}$ B, Ciudad Autónoma de Buenos Aires, Argentina (1025) [psendon@yahoo.com].

Journal de la Société des Américanistes, 2010,96-2, pp. 133-179. O Société des Américanistes. 
time - such as it is narrated by the members of the ayllu Collana from the district of Marcapata (province of Quispicanchi, Cusco) in relation to three kind of sources: a) the archaeological information about the geographical and spatial localization of the mortuary monuments which received that name in the Central Andes; b) the ethnological information about other versions of the myth registered among other indigenous-peasant populations from Southern Peru and the Bolivian altiplano; c) the ethnohistorical information which, in relation with the myth, has been registered by several scholars. The main objective of the review is to lay the foundations of a comparative perspective of the myth with the aim to transcend the specificities of a case study. [Key words: ch'ullpa, mortuary monuments, beings of the pre-solar time, mythology, Southern Peru, Collasuyu.]

\section{INTRODUCCIÓN}

En 1931 Alfred Métraux dio a conocer una de las primeras versiones ${ }^{1}$ del mito de los ch'ullpa ${ }^{2}$ registrada durante su estadía entre los chipaya del sur de la provincia de Carangas (departamento de Oruro, Bolivia). Según cuenta la leyenda, en los tiempos antiguos vivían los ch'ullpa, seres que construían sus casas con las puertas orientadas al Oeste, por donde, entonces, el sol acostumbraba salir. Un día decidieron cambiar la orientación de las puertas de sus viviendas en dirección opuesta. El sol siguió el curso que conocemos y en su peregrinaje quemó a todos los ch'ullpa, salvo a una pareja que se había sumergido en el agua para escapar de la destrucción total. Siguiendo el curso de los ríos, la pareja se afincó en la región habitada por los chipaya. Consagrando sus noches a los trabajos que los humanos realizan durante el día, los ch'ullpa se sumergían en las profundidades de las aguas cuando el sol despuntaba en el horizonte, y allí permanecían hasta que el astro se ocultaba detrás de las montañas. En una oportunidad, un extranjero descubrió este pueblo peculiar y se lo comunicó al cura de su aldea quien, curioso ante el acontecimiento, se dirigió en seguida al escenario de los hechos y bendijo a los ch'ullpa, deshaciendo así el sortilegio del que habían caído presos. Tras este acto, pudieron entregarse a las tareas diurnas a las que se dedican los hombres, y se convirtieron así en chipaya, quienes, a diferencia de sus antepasados, además de cultivar la quinua y algunos otros cereales, se especializaron en la ganadería (Métraux 1931, pp. 112-113). En virtud del lazo ascendente que los une con los ch'ullpa, las poblaciones aymara circundantes se refieren de manera despectiva a los chipaya mediante la expresión ch'ullpa puchu o « sobra del ch'ullpa » (ibid., p. 109), aludiendo así a una condición humana relativa. Precisamente, si desde la perspectiva chipaya el mito puede ser leído como un relato sobre sus antepasados, desde el punto de vista aymara esta misma asociación hace de los chipaya los herederos directos de una prehumanidad cuyos atributos contrastan con la presente ${ }^{3}$. 
El distrito de Marcapata se encuentra ubicado en la porción oriental de la provincia de Quispicanchi, a la vera del flanco septentrional del macizo del Ausangate que, desde el Cusco y bajo las denominaciones de cordilleras de Carabaya y Vilcanota, se extiende hacia el altiplano boliviano. El territorio distrital limita, al sur, con la provincia de Canchis, al oeste con el distrito de Ocongate, al norte con el distrito de Camantí - porción de ceja de selva y antesala del departamento de Madre de Dios - y al este con la provincia puneña de Carabaya. Desde la perspectiva de un eje Sur-Norte, el territorio del distrito $\left(5000 \mathrm{~km}^{2}\right)$ se presenta como un gigantesco tobogán que desciende desde el Ausangate, por encima de los $5000 \mathrm{~m}$ sobre el nivel del mar, hasta el piedemonte amazónico, por debajo de los $1500 \mathrm{~m}$ sobre el nivel del mar. El río Marcapata, que en sus cursos medio e inferior recibe el nombre de Araza, desemboca hacia el Este en el río Inambari y este último, limítrofe entre los departamentos de Puno y Cusco, confluye hacia el norte con el Madre de Dios. La población marcapateña, aproximadamente 6000 individuos, está dedicada a una agricultura diversificada, según el ritmo estacional impuesto por los pisos ecológicos que comprenden su territorio, y a la ganadería en aquellas porciones de mayor nivel altitudinal (Yamamoto 1981).

La población marcapateña se encuentra organizada en ocho comunidades campesinas y en cuatro ayllus ${ }^{4}$. Mientras que cuatro de las comunidades han sido reconocidas como tales durante la década de 1980 y ocupan un lugar relativamente periférico en el territorio distrital, las otras cuatro llevan los mismos nombres que el de los cuatro ayllus en los que estaba dividido el territorio marcapateño desde al menos fines del siglo xviII: Collana Marcapata, Sahuancay, Puiqa y Collasuyu. El lugar que ocupan estos ayllus en la vida social del distrito no se reduce a una caprichosa inercia de las nomenclaturas. En efecto, los ayllus en cuestión se relacionan entre sí en virtud de un orden jerárquico reproducido en la forma en que han sido nombrados. Entre cada uno de estos ayllus y las comunidades de reconocimiento reciente existe un vínculo genealógico, ya que las segundas son concebidas como sus "hijas». Asimismo, cada uno de los ayllus es el depositario de cada uno de los santos patrones (San Francisco de Asís, Collana Capaq, Virgen Purificada y Virgen Concebida) titulares de sus respectivas capillas, y de cada uno de los apu mayores (Pachatusan, Piñuta, Sacsayhuaman y Huahuallani) protectores de sus respectivos territorios ${ }^{5}$. La relación jerárquica entre los ayllus, así como el vínculo que mantienen con sus santos patrones y $a p u$, se expresa cabalmente cada cuatro años en ocasión de la celebración del wasichakuy (" hacerse de casa »), momento en el que todas las familias marcapateñas realizan un peregrinaje hacia el centro del pueblo (llaqta uhu) con el objeto de participar en el cambio del techo de paja de la iglesia local en el marco de una efervescencia ritual que se prolonga a lo largo de toda una semana (Champi Ccasa 1996; Sendón 2004). El rol de estos ayllus no se restringe a una aparición ritual esporádica sino que, por el contrario, su latido se deja sentir 
en todas las esferas de la vida social marcapateña, incluso en el universo de la mitología. Precisamente, en el ayllu Collana, principal en la jerarquía, pudimos escuchar, con algunas variaciones significativas, el mismo mito que hace poco más de siete décadas y a varios cientos de kilómetros de distancia le relatara a Métraux un indio chipaya tenido por el más anciano de su tribu ${ }^{6}$.

El mito de los ch'ullpa en Marcapata remite a un importante corpus bibliográfico sobre los Andes Centrales al que es preciso referirse para su mejor comprensión, análisis y caracterización. Los siguientes dos apartados están dedicados a una parte de dicho corpus con el fin de introducir el material marcapateño a la luz de sus homólogos quechua y aymara ${ }^{7}$.

\section{« LAS » CH'ULLPA EN EL REGISTRO ARQUEOLÓGICO}

Parafraseando a John Hyslop (1977, p. 150), una primera aproximación al tema de los ch'ullpa debe tener en cuenta que el término en sí mismo ha significado cosas diferentes ${ }^{8}$ para distintas personas: bajo la misma palabra se ha definido una " cultura prehistórica », un " estilo de cerámica », varias clases de " enterratorios » y hasta un « tipo de cestería ». Efectivamente, a lo largo del tiempo diversos viajeros, arqueólogos, historiadores, etnógrafos y etnólogos se han pronunciado en repetidas oportunidades sobre alguna u otra de las características que parecieran definir a los ch'ullpa, siendo una de las más destacadas aquella que atañe al registro arqueológico.

Hasta la década de 1930, salvo las excepciones mencionadas en la introducción, la palabra ch'ullpa era empleada en la literatura especializada para referirse a las tumbas funerarias erigidas sobre el terreno que, mayoritariamente, se encuentran localizadas en el altiplano boliviano. Estas tumbas presentan una gran variación en cuanto a su fisonomía, diseño, antigüedad, estatus, función, ubicación, orientación, distribución en el paisaje, material con el que fueron construidas, objetos conservados en su interior y no es nuestra intención detenernos en los debates suscitados sobre la materia. Sí es preciso, por razones que se harán evidentes más adelante, remitirnos a aquellos trabajos que más explícitamente se han referido al fenómeno " ch'ullpario » en relación con dos problemas estrechamente ligados: la ubicación geográfica de los monumentos y la presencia de algún rastro relativo al mito de los seres del tiempo pre-solar.

Uno de los primeros informes modernos ${ }^{9}$ acerca de la existencia de monumentos funerarios denominados ch'ullpa proviene de la pluma de David Forbes, quien identificó un importante número de tumbas erigidas sobre el terreno en la región lacustre de la provincia de Carangas (villa de Curahuara), el lago Titicaca (isla de Quebaya) y los pueblos de Corocoro y Caquingora (provincia de Pacajes) del departamento de La Paz (Forbes 1870, pp. 239-240) ${ }^{10}$. Existen dos observaciones en el escrito de Forbes que, indirectamente, se relacionan con su discusión sobre las ch'ullpa. En primer lugar, una breve mención a una serie de pequeños 
montículos de piedra erigidos por indios llameros en el paso de Huaylillos durante sus travesías entre La Paz y Tacna, en el sur peruano (ibid., p. 238) y, en segundo lugar, una referencia a que las ruinas de las ciudades antiguas aymara antes de la conquista española eran denominadas genéricamente como « pueblos de los gentiles » (ibid., p. 259). Siete años más tarde, Squier (1877) identificó y describió varios ejemplares de ch'ullpa localizadas en los actuales distritos de Palca y Acora (provincias de Lampa y Puno), y en los alrededores de los lagos Umayo (provincia de San Román) y Titicaca del departamento de Puno. $\mathrm{Al}$ referirse al sitio de Vilque, ubicado en extremo septentrional del lago Umayo, Squier subrayó la convocatoria que tenía su feria anual, a la que llegaban muleteros de regiones tan lejanas como Cusco, Tucumán y las provincias de la Plata (ibid., p. 376). Squier caracterizó a las ch'ullpa como sepulcros dedicados a los antepasados y estimó la posibilidad de que este tipo de estructura estuviera confinado al Collasuyu, siendo patrimonio exclusivo del área aymara - aunque él mismo reconoce haber visto estructuras semejantes en el abra de La Raya y conocido acerca de su existencia en el departamento peruano de Junín (ibid., pp. 388-389) ${ }^{11}$. Esta adjudicación no deja de ser problemática y no pasó desapercibida a investigadores posteriores (ver infra). Por el momento, baste decir que a comienzos del siglo pasado Adolph Bandelier, en un escrito dedicado al problema de la antigüedad de los enterratorios peruanos, cita un fragmento de una carta pastoral contra las idolatrías de los indios del Arzobispado de Lima de mediados del siglo XviI en la que se menciona que los sitios de enterramiento de los indígenas, ubicados en las tierras de sus ancestros, eran denominados machais y zamay y, en su propio análisis, los vincula con las ch'ullpa de la región del Titicaca (Bandelier 1904a, pp. 218, 225) ${ }^{12}$. Sobre la región lacustre del Titicaca, Koatí y Copacabana dirá un año más tarde que sus límites son indefinidos en términos de la coexistencia de poblaciones quechua y aymara, así como también que la influencia inca en la zona fue más bien limitada (Bandelier 1905, p. 460). De igual modo, en su análisis de la historia de Juan Rubio (nota 3), Bandelier recuerda que Juan de Betanzos escuchó acerca de la historia de un personaje similar a Tunupa en el actual distrito de San Pedro de Cacha (provincia de Canchis), en donde la lengua que se hablaba por entonces habría consistido en una mezcla del quechua y aymara y que, en todo caso, los habitantes de la zona pudieron haber escuchado las tradiciones provenientes del Collao (Bandelier 1904 b, p. 618) ${ }^{13}$. En resumen, aunque estos primeros informes sobre ch'ullpa están más bien concentrados en las construcciones funerarias del altiplano boliviano, se advierte que ellas no se restringen exclusivamente a esta zona, cubriendo un espacio que pareciera estar articulado por la dinámica de movilidad de poblaciones dedicadas al intercambio interregional mediante el empleo de llamas o mulas. Asimismo, el término en cuestión no sólo designa a los monumentos erigidos en honor de los antepasados, sino también a aquellos seres que moraban en la tierra antes de la salida del sol. 
Las observaciones de Erland Nordenskiöld acerca de su viaje entre los territorios limítrofes de Perú y Bolivia a comienzos del siglo pasado apuntan directamente a esta serie de consideraciones. La ruta seguida por Nordenskiöld estuvo dedicada a las pendientes orientales de los Andes en dirección a los bosques tropicales, entre los ríos Madre de Dios y Beni. Sobre el curso inferior del río Marcapata el autor identificó la presencia de indígenas tacanahablantes autodenominados " arasa » quienes, ubicados al sudoeste de asentamientos huachipaire, estaban dedicados a la explotación del caucho y, en menor medida, a la extracción aurífera (Nordenskiöld 1906, pp. 106, 108). Hacia el Este, en las regiones altitudinales más elevadas habitadas por poblaciones quechuahablantes, Nordenskiöld excavó tumbas y grutas sepulcrales, denominadas ch'ullpa, localizadas en los valles de Quiaca, Ollachea, Queara, Corani y Macusani (departamento de Puno). Según el autor, estas construcciones derivan de la tradición aymara, ya sea porque los valles en cuestión fueron originalmente habitados por poblaciones aymara o por grupos del altiplano desplazados por los quechua que más tarde adoptarían su lengua (ibid., p. 112). Sea como fuere, lo cierto es que ninguna ch'ullpa o cueva sepulcral se encuentra al este o al oeste de las zonas altitudinales más elevadas de los Andes, siendo patrimonio de poblaciones asentadas, mayoritariamente quechua, y dedicadas a la crianza de ganado (ibid., p. 114). El descenso de los valles en dirección Este, hacia el piedemonte amazónico, se presenta como un límite para la crianza del ganado altoandino, en particular de llamas, y allí, al menos en los valles que visitó, Nordenskiöld no encontró estructuras del tipo ch'ullpa (ibid.). Las poblaciones asentadas sobre los ríos Inambari y Tambopata eran designadas por los quechua bajo el término genérico de $c h$ 'unchu, identificados por Nordenskiöld como yamiaca, atsahuaca y guarayo (ibid., pp. 121-122) ${ }^{14}$. Además, entonces, de verificar la existencia de ch'ullpa en zonas aledañas al universo aymara y de relacionarlas con grupos dedicados a la agricultura de altura y a la crianza de camélidos, este escrito temprano vincula unas y otras con el universo de la selva, presentándose este último, eso sí, como un límite aparentemente infranqueable para ambas. Por otra parte, el registro de los sepulcros no se reduce exclusivamente a una enumeración paisajística ya que, casi al pasar, Nordenskiöld llamó la atención acerca de una costumbre de los indios consistente en enterrar el pelo de un individuo, o cosa semejante, en una tumba antigua con el objeto de causarle algún mal o enfermedad (ibid., p. 111).

A pesar de que algunos autores se mostraron reacios a reconocer en las ch'ullpa túmulos o sepulturas, y prefirieron, en su lugar, caracterizarlas como casas, habitaciones o pueblos abandonados anteriores a la conquista española (Posnansky 1912, p. 80; 1918, p. 7), lo cierto es que, a medida que se fueron ampliando, las investigaciones arqueológicas descubrieron cada vez más construcciones de este tipo en muchos sitios de los Andes Centrales ${ }^{15}$. Cronológicamente, al menos, resulta ilustrativo mencionar en relación con los 
problemas desplegados hasta el momento algunos de los trabajos en cuestión. Las construcciones del sitio Tunan-Marka o Jatun-Malka, localizado en la provincia de Jauja (departamento de Junín) en el Perú central, no sólo han sido identificadas con el ciclo de edificaciones « chullparias » anterior a los incas, sino también con edificaciones semejantes construidas por los pastores de altura de la región, la organización en ayllu y el culto de los muertos (Gutiérrez Noriega 1935, pp. 105-108) ${ }^{16}$. Entre las ch'ullpa identificadas en el departamento de Puno y zonas aledañas (Vásquez et al. 1935; Vásquez 1937; Tschopik 1946) ha llamado nuestra atención aquella que, localizada en la colina de Wakani-Wichinka del distrito de Pomata (provincia de Chuchito), lleva el nombre de Lari-Amaya (Franco Inojosa y González 1936, p. 183), que podría traducirse como "sepultura de los muertos afines de la puna incivilizados ${ }^{17}$. Desde las cabeceras del río Paucartambo, y en dirección hacia el Este, se han identificado ch'ullpa asociadas a monumentos funerarios en diversos sitios de los distritos de Ocongate, Marcapata y el abra Walla-Walla - punto divisorio de aguas hacia los ríos Ucayali y Madre de Dios (Franco Inojosa 1937). Las investigaciones y balances realizados por Stig Rydén demuestran que el término ch'ullpa no se restringe a las torres funerarias antiguas del altiplano boliviano, sino que también detenta un sentido genérico que incluye las estructuras modernas a las que los indígenas dedican sus sacrificios (Rydén 1947, p. 340). De igual modo, las estructuras en cuestión - antiguas o modernas - tampoco se circunscriben a la región circunlacustre de Bolivia, sino que se encuentran en sitios tan alejados como, hacia el Norte, las provincias peruanas de Huaraz, Canta, Huarochirí y Jauja (departamentos de Ancash, Lima y Junín) y, hacia el Sur, el río San Juan en el noroeste argentino (ibid., pp. 339, 403, 447-450). La distribución de las ch'ullpa hacia el norte del lago Titicaca (por ejemplo las provincias de Carabaya y Quispicanchi) parecería coincidir con el avance de poblaciones aymara en tierras quechua (ibid., p. 410), pero su presencia en sitios más alejados presenta un problema que no escapó a la atención de Rydén: de los registros citados no es claro si el término ch'ullpa era empleado por los habitantes locales o por los mismos autores familiarizados de antemano con las construcciones del lago Titicaca (ibid., p. 450) ${ }^{18}$. Ello no es un problema menor. Para John Hyslop - concentrado en las edificaciones del sudoeste del Titicaca - las edificaciones ch'ullpa forman parte de la tradición de poblaciones nativas pre-incaicas del altiplano (Hyslop 1977, p. 160). En rigor, el período al que está asociado el surgimiento de la edificación "chullparia » es alrededor del año $1100 \mathrm{DC}$, coincidente con un proceso de convulsión cultural durante el cual, tras la caída de Tiahuanaco, el aymara reemplazó al puquina como lengua principal, el cisma político estuvo a la orden del día, el pastoralismo se intensificó y un nuevo sistema de asentamientos en la cima de las montañas comenzó a generalizarse (ibid., pp. 162-163). Más allá de la problemática relativa a la influencia incaica posterior (ibid., p. 170), volvemos a apreciar aquí que la discusión sobre las ch'ullpa se 
relaciona con la actividad pastoril y, como una de sus variadas funciones es la de marcadores territoriales (ibid., p. 154), resulta en cierto modo difícil no rememorar aquellos montículos de piedra erigidos por los llameros en sus travesías entre Tacna y La Paz, sobre los que David Forbes se había pronunciado cien años antes ${ }^{19}$.

La asociación entre las estructuras « chullparias » y el área aymara fue puesta en cuestión por William Isbell (1997, pp. 137-215) al identificar la existencia de lo que denominó "sepulcros abiertos» no sólo en el altiplano boliviano sino también en los departamentos peruanos de Cusco, Ayacucho, Junín, Arequipa, Huancavelica, el callejón de Huaylas y, más al norte, el valle del río Marañón. La discusión de Isbell sobre los « sepulcros abiertos » en los Andes Centrales se relaciona con el problema del surgimiento y constitución prehistórica del ayllu, agrupamiento social cuyos atributos definitorios son, de acuerdo con el autor, la accesibilidad de sus miembros a recursos comunales compartidos, el reconocimiento de una jerarquía social expresada en el idioma del parentesco y, fundamentalmente, la veneración de un ancestro fundador (ibid., p. 99). Isbell subraya que el término ch'ullpa es empleado en el centro y sur peruano y en el altiplano boliviano para designar los monumentos sepulcrales abiertos, y que su uso comenzó a generalizarse recién en el siglo XIX, sin que exista en las crónicas del siglo XVI mención alguna a él (ibid., pp. 161-163). En este sentido, de acuerdo con Isbell, las ch'ullpa no son sino la forma altiplánica del sepulcro abierto y, en calidad de sepulcro abierto, no son patrimonio exclusivo del horizonte aymara ya que, por ejemplo, en el valle del río Marañón en el norte del Perú se encuentran monumentos cuya antigüedad antecede a sus pares altiplánicos en quinientos e incluso mil años - ubicándose en la franja temporal que los arqueólogos denominan « intermedio temprano » (ibid., p. 215).

Dos de los pronunciamientos de Isbell deben ser reexaminados a la luz de la bibliografía disponible. En primer lugar, no es verdad que el término ch'ullpa comience a ser empleado recién en el siglo XIX ya que, por ejemplo, aparece consignado en el diccionario de la lengua aymara de Ludovico Bertonio de $1612^{20}$. En segundo lugar, investigaciones recientes han sostenido que la tradición de sepulturas abiertas del norte peruano no pueden relacionarse directamente con la tradición del altiplano sur; debido a que construcciones similares cercanas a San Pedro de Atacama (Chile), que podrían ser más antiguas, no pertenecen a la categoría de torres funerarias ya que carecen de enterramientos humanos - mientras que sucede lo contrario con aquellas recientemente fechadas en Arequipa y el oeste del Cusco (Kessely y Pärssinen 2005, p. 384) ${ }^{21}$.

De esta reseña - que no pretende ser exhaustiva - sobre la literatura arqueológica dedicada a las ch'ullpa, es posible advertir una serie de características sobresalientes. En primer lugar, en calidad de tales, es decir de ch'ullpa, ellas están significativamente asociadas con el altiplano boliviano, con el universo aymara (entendido de manera genérica) y con aquellas regiones sobre las que pudo haber 
ejercido alguna influencia. En segundo lugar, en calidad de monumentos funerarios, están íntimamente vinculadas no sólo con el culto a los antepasados sino también con lo que ellos suponen, la organización en ayllus. En tercer lugar, por extenderse sobre un espacio ecológico y geográfico transitado por grupos de pastores, parecieran poner en relación los territorios del altiplano boliviano y la sierra peruana con los del piedemonte amazónico y la ceja de selva. Finalmente, su temporalidad, difícil de asir, remite a un tiempo anterior. Una manera de introducir este problema es mediante el análisis del segundo de los sentidos generales de la palabra ch'ullpa, aquel relacionado, precisamente, con los seres del tiempo pre-solar.

\section{LOS CH'ULLPA EN EL REGISTRO MITOLÓGICO}

Las ch'ullpa no sólo están inscriptas en el paisaje sino también en la memoria de los individuos que lo observan, que transitan y que viven en él. Las diversas versiones del mito de los ch'ullpa - y el aparato crítico del que forman parte tienden a asociarlos con unos seres que habitaban la tierra en un tiempo anterior al de la salida del sol y, en virtud de ello, a una prehumanidad que carece de los atributos que caracterizan a la humanidad actual. Dichas versiones, a su vez, reproducen en sus rasgos estructurales aquella otra registrada por Métraux entre los chipaya. Sin embargo, sería ciertamente injusto arrojar en un mismo costal los relatos en cuestión bajo la categoría « mito de los ch'ullpa », ya que ellos presentan una serie de precisiones y matices que no sólo amplian las posibilidades de caracterización y definición de estos seres sino que, al hacerlo, desvirtúan sus atributos en principio sobresalientes.

Entre los indígenas de Kauri del distrito de Ccatccha (localizado, en Quispicanchi, entre Urocs y Marcapata), Bernard Mishkin recopiló un relato según el cual las tierras de Kauri eran propiedad de las divinidades de los cerros o auki ${ }^{22}$, quienes vivían en la oscuridad alumbrados bajo la pálida luz de la luna hasta que un día sus profetas les anunciaron su fin debido a la aparición de un cometa encendido que se aproximaba desde el Este. Algunos auki se escondieron en la cima de sus cerros pero la mayoría, armados con arcos y flechas, se dirigieron hacia el Este para dar batalla al sol, a quienes los indígenas denominaban también Inti Huayna Ccapac. Sólo aquella porción de la población que se alzó en armas fue destruida. Aquellos que permanecieron en las cimas de las montañas escondidos en sus ch'ullpa lograron subsistir, y aún hoy suelen vengarse de los hijos de Huayna Ccapac causándoles una serie de enfermedades como picazón, viento (soq'a) e hinchazón (pukyo) (Mishkin 1940, p. 235) ${ }^{23}$. Mishkin también menciona otro mito sobre Huayna Ccapac o Manco Ccapac quien, en calidad de héroe cultural, compite con Colla Ccapac arrojando una vara por el aire. Se dice que el primero venció al segundo por ser más poderoso ya que era dueño del maíz, 
mientras que Colla Ccapac sólo poseía llamas. El sitio de la contienda fue el abra de La Raya (ibid., pp. 235-236). Visiblemente ambos mitos hacen referencia a una serie de límites ecológicos y culturales (que volverán a repetirse de diversas maneras en otras versiones) entre agricultores quechua, pastores altoandinos del Collasuyu y selváticos del Antisuyu - subsumidos en la figura de los auki rebeldes que, en su lucha contra el sol, disponían sólo de arcos y flechas ${ }^{24}$.

Las versiones del mito de Viracocha recopiladas por John Rowe (1946) también involucran a seres del tiempo pre-solar. Aunque no son denominados ch'ullpa, ellos invitan a extender el horizonte comparativo del relato. En un primer momento Viracocha creó un mundo de cielo y tierra que dejó en la oscuridad, y de las rocas de las montañas una primera humanidad de gigantes a quienes más tarde destruyó. Luego creó una nueva raza de seres a su propia medida para reemplazar a los gigantes y, asimismo, dio luz al mundo haciendo emerger el sol y la luna del lago Titicaca. Por entonces, la luna era más brillante que el sol y éste, celoso de ella, le arrojó un puñado de ceniza en su rostro para oscurecer su brillo. Viracocha, quien tenía el aspecto de un viejo y llevaba un bastón, siguió camino hacia el Titicaca y más tarde, en dirección al Oeste, hacia el Océano Pacífico. En su trayecto se detuvo en el pueblo de Cacha y sus habitantes, quienes no querían a los extraños, lo apedrearon. Entrado en cólera, el viejo hizo caer fuego del cielo y atemorizó a sus enemigos, de quienes finalmente se apiadó (Rowe 1946, pp. 315-316). Tschopik (1946, pp. 570-571) vincula incluso más explícitamente los ch'ullpa con Viracocha, quien, cual Tunupa, es concebido como un hombre blanco, viejo y barbudo que, llegado desde el norte, se opuso a la práctica de la poligamia y al consumo de chicha. Junto con estas prácticas, el autor menciona una versión del mito en la que se les atribuye el origen de las plantas cultivadas (ibid., p. 571). Si bien en otra versión, recopilada entre la población aymarahablante de la provincia de Chucuito (Puno), se relata que los ch'ullpa cultivaban efectivamente sus territorios en la oscuridad de la noche, se precisa que ellos, seres dementes y paganos, no sabían cocinar y tenían por costumbre ingerir los alimentos crudos (Tschopik 1948, pp. 113-114) ${ }^{25}$.

Las versiones q'ero y qotobambina (provincias de Paucartambo y Calca, Cusco) del mito de Inkarri y Collari siguen una senda similar a los relatos mencionados sobre Huayna Ccapacc y Viracocha. Antiguamente la tierra era habitada por los ñavpa machu (« viejos abuelos antiguos »), seres poderosos que podían mover rocas gigantescas a su voluntad y convertir montañas en llanuras. Con el tiempo, su soberbia hizo montar en cólera al roal ( jefe de los apu»), quien creó el sol para incinerarlos y, más tarde, a la primera pareja de Inkarri y Collari. Algunos de los antiguos sobrevivieron y se convirtieron en soq'a, seres que al caer la tarde o en las noches de luna llena vagabundean por los cerros (Núñez del Prado 1958, pp. 12-13). En el relato de Qotabamba es Dios quien, tras varios intentos de conciliación - los cuales involucraron la intermediación de su 
hijo Cristo, el ave hak'achu, una paloma (urpi) y un colibrí (q'enti) - dejó caer sobre los antiguos una lluvia de fuego (Núñez del Prado Béjar 1970, pp. 65-66). Los sobrevivientes de esta primera humanidad son designados como soq'a machu, soq'a paya (« ñawpa masculino » y «ñawpa femenino ») - quienes mantienen relaciones sexuales con los humanos causándoles graves males - y soq'a pukyu («manantiales malignos ») (ibid., pp. 84-87) ${ }^{26}$. En otra versión del mito q'ero, los ñawpa machu - « adoradores de la luna » - están asociados explícitamente con los seres que habitan en cavernas y pequeñas ch'ullpa y con sus descendientes contemporáneos que viven en la selva bajo la protección de la sombra de los árboles (Morote Best 2005, pp. 289-290) ${ }^{27}$. Inclusive, los ñawpa son caracterizados como seres que tienen a las perdices por gallinas, a los venados por cabras y a los zorrinos por cerdos y, si bien sus campos de cultivo se encuentran sembrados por plantas salvajes, conocieron el añu, la única especie comestible hasta nuestros días (ibid., p. 294) ${ }^{28}$. Los indígenas de Hatun Kuyo (Calca) concuerdan en que las tumbas (machu wasi) diseminadas en sus territorios pertenecen a la misma categoría de seres identificados en las regiones circunvecinas. En este caso, sin embargo, se especifica que los machu, paya o awki de ambos sexos adoraban a una luna de una especie diferente a la que conocen los mortales, así como también a un sol de cobre (anta inti) que los regaba con una luz tenue y rojiza ${ }^{29}$. Los machu, que vivían en pueblos semejantes a los actuales pero localizados en las alturas de los cerros, escondieron sus riquezas y destruyeron los objetos que eventualmente pudieran haber sido utilizados por los hombres cuando su sol de cobre se oscureció mediante una lluvia de fuego (nina para) enviada por Dios para destruirlos. Según los habitantes de Hatun Kuyo, los únicos sobrevivientes de la calamidad son los q'ero de Paucartambo, razón por la cual son conocidos como q'ero machu (Casaverde Rojas 1970, pp. 150-154) ${ }^{30}$. Sin embargo, el machu es un ser ambivalente: si se comporta de manera benéfica se lo llama como tal y si lo hace maléficamente se lo designa soq'a machu o simplemente soq'a (ibid., p. 156). Los objetos de estos últimos que se encuentran cerca de las cuevas o tumbas son considerados phiru ( fieros » o " peligrosos ») y, como tales, causantes de enfermedad (ibid., p. 163).

El análisis de Duviols (1973) de documentos sobre visitas de idolatrías en las provincias de Recuay y Cajatambo (departamentos de Ancash y Lima) permite extender aún más el horizonte comparativo sobre los ch'ullpa. A comienzos del siglo XVII los pueblos de la sierra de la arquidiócesis de Lima conjugaban la presencia de dos « grupos étnicos » diferenciados denominados huari y llacuaz, los primeros naturales de las zonas que ocupaban y los segundos migrantes (ibid., p. 153). El término huari o wari significa, en quechua, "hombre antiguo", " salvaje » e « indómito » y, en aymara, " animal salvaje » o "líquido ». En Bolivia el término está asociado a la noción de purunruna ( " hombre antiguo ») y en el Cusco es sinónimo de machu, mallqui o "gentil ». Huari también designa a los antiguos pobladores que permanecen en las tumbas antiguas vigilándolas, a 
las enfermedades de los huesos y de los manantiales a ellos asociados, a una especie de monstruo - también denominado lari - que, cuando se lo invoca, se presenta bajo la forma de un gato que desprende ráfagas de fuego de sus ojos y pelos y, finalmente, a un Dios poderoso - incluso a seres antropomorfos de elevada estatura y gran fuerza -, al que se le atribuye la construcción de represas y canales para la prosperidad agrícola (ibid., pp. 154-155) ${ }^{31}$. Si en calidad de ñawpa machu los ch'ullpa presentan características que los asemejan a los huari, estos últimos, en calidad de creadores de la agricultura, se diferencian de ellos ya que de acuerdo con su origen mítico fueron creados por el sol - aunque también se les ha atribuido un origen costeño, y por lo tanto acuático, asociado con la explotación de cocales (ibid., pp. 160-161) ${ }^{32}$. Entre sus cultos, destacan los sacrificios en las cuevas (mach'ay) o sepulcros de los mallqui (ibid., p. 165). Los llacuaces, por su parte, de origen foráneo, son pastores nómadas ligados a la crianza de camélidos en las altas cumbres (ibid., pp. 166-167). Entre sus cultos se encuentra la veneración a las casas de piedra ofrecidas al rayo - de quienes son hijos - por su auspicio en la procreación del ganado (ibid., p. 172). Los conquistadores llacuaces proceden de las altas mesetas del este y, en sus movimientos hacia el Oeste, se asentaron en los pisos altitudinales más elevados. Desde la perspectiva de la relación huari-llacuaz, aquellos atributos que en un primer momento parecían identificar a los huari con los ch'ullpa retroceden, o incluso se invierten, pasando a formar parte del ethos llacuaz. Pareciera que los antiguos huari, también denominados llacta (del quechua llaqta, " pueblo » o " villa »), no consideraron a sus conquistadores llacuaces como una clase superior sino como un grupo de advenedizos, sin pueblo o manallactayoc (manallaqtayoq, "sin pueblo ») (ibid., pp. 184-185) ${ }^{33}$.

Los problemas planteados por Duviols remiten a cuestiones similares provenientes del Collasuyu, en particular aquellas relacionadas con las concepciones de espacio y tiempo. Antes de la invasión inca, los territorios comprendidos sobre el eje acuático articulado a lo largo del río Azángaro, el lago Titicaca, el río Desaguadero y el lago Poopó fueron conceptualizados en términos de un modelo dual en el que cada una de sus mitades lleva las denominaciones de urcosuyu y umasuyu (Bouysse-Cassagne 1986, p. 203). Una primera aproximación demuestra que el sentido de ambos términos y su mutua relación refleja, de manera invertida, lo expresado en el par huari-llacuaz. La sociedad aymara - pluriétnica de por sí - designaba mediante urco a sus propios territorios, las zonas altas y frías donde practicaban la ganadería (ibid.). El patrón de residencia durante este período, a la manera de aglomeraciones urbanas fortificadas ubicadas en los sitios más elevados, coincide con la era de los auca runa (o awqa runa, " hombre enemigo »), sociedad de guerreros sin tierra asociados con la violencia, la agresión, el dominio masculino y el sometimiento a la ley del más fuerte (ibid., p. 205). Los uru y pukina de las regiones lacustres pertenecen, por su parte, a la categoría uma que, entre otras cosas, también hace referencia a los valles de las tierras bajas 
orientales, al ambiente húmedo y acuático y a una cierta idea de feminidad (ibid., pp. 206-207). Más allá del Collao, los valles de las tierras bajas en dirección al Pacífico y al Amazonas fueron igualmente sometidos a la misma lógica clasificatoria. Mientras que el hombre urco se piensa a sí mismo como extremadamente generoso, considera a sus pares de los valles orientales como gente mezquina, que evita el trato social prefiriendo comer sola y no hablar (ibid., p. 210). Entre ambos términos, además, existe una zona intermedia denominada taypi («centro », chawpi en quechua) que, relacionada con el lago Titicaca, también remite a la categoría de tiempo. Precisamente, la primera edad del tiempo es designada taypi y la figura central en ella es el dios Tunupa, personaje asociado con el fuego y las erupciones volcánicas quien, en su peregrinaje a lo largo del eje acuático cae preso de la seducción de mujeres peces (BouysseCassagne y Harris 1987, pp. 19, 21). A esta edad le sigue otra, designada puruma. El término purun o puruma define a las tierras de barbecho o desérticas y está asociado a la idea de virginidad y salvajismo. En otras acepciones, el vocablo es sinónimo de chuquila y larilari, es decir, gente cimarrona que vive en la puna sosteniéndose de la caza de animales silvestres, tratándose también del hombre de las tinieblas que carece de ley y gobierno, ubicado conceptualmente en las antípodas de los seres solares. En esta edad, Tunupa vuelve a aparecer desterrando a unos personajes nocturnos, los hapiñuñu, hacia las cimas de los cerros nevados (ibid., pp. 22, 24) ${ }^{34}$. La tercera de las edades, anterior al tiempo incaico, es awqa, y se trata de un tiempo de guerra en el que los hombres vivían en confusión y desorden (ibid., p. 28). La mitología, entonces, pone sobre un mismo plano las figuras de los purun, hapiñuñu, chuquila, larilari, ch'ullpa y los wari, considerados desde estas latitudes como seres que apenas conocían la agricultura (ibid., p. 23) ${ }^{35}$.

Los indígenas de Pinchimuro (distrito de Ocongate, Quispicanchi) también conciben su historia en edades, siendo la segunda de ellas la época de los ñawpaq o machula - igualmente denominados « gentiles ", chulpay o machu inka (Gow y Gow 1975, p. 156). Durante ese tiempo, los hombres, que vivían en la oscuridad y sin Dios, tenían la fisonomía de los humanos actuales y eran poseedores de alpacas (ibid., pp. 142-143) ${ }^{36}$. Un día el sol apareció en el horizonte y quemó a los machula convirtiéndolos en piedras, salvo a aquellos que pudieron huir hacia la selva en dirección a la regíon de Madre de Dios, al igual que las alpacas que se sumergieron en las profundidades de las lagunas - unos y otras volvieron a renacer en la era del Dios churi (o «Dios hijo ») (ibid., pp. 157-159). Aquellos selváticos que pudieron escapar del cataclismo son denominados genéricamente ch'unchu y, como tales, son representados en una de las comparsas de danzantes que integran la peregrinación anual al santuario del Señor de Quyllurit'i, al pie del Ausangate. Cuenta la leyenda que para el Señor los ch'unchu de Paucartambo eran sus predilectos por ser los antepasados de los campesinos de Ccatcca, primeros en llegar al lugar del milagro. Es decir, los ch'unchu son los descendientes 
de los machu que pudieron escapar por los ríos hacia la selva y, como tales, son concebidos a la vez como ancestros de parte de la población actual. A ellos están asociadas ideas de pobreza e igualdad. En rigor, en estos contextos los campesinos hablan de los wayri ch'unchu para diferenciarlos del resto de los indios de la selva (Gow 1974, pp. 71-73). Los machula representan a los ancestros pobladores de las alturas que, en calidad de wayri ch'unchu, son considerados benévolos y, en calidad de soq'a machula, malévolos (ibid., p. 79) ${ }^{37}$.

Los runakuna (" hombres ») de Sonqo (distrito de Colquepata, provincia de Paucartambo) denominan a sus ancestros machula aulanchis ( nuestros abuelos antiguos »), de quienes dicen que habitan pequeñas torres en ruinas (ch'ullpa) localizadas en las laderas del Antaqaqa, el apu local más venerado. Los huesos de estos seres poseen cierta capacidad de animación y son conservados, en particular sus cráneos, ya que proveen de bienestar y protección (khuyay o kuyray). Los machula masculinos detentan el rol de ancestros protectores haciendo crecer la papa - el viento de sus ch'ullpa es beneficioso para los campos - y, en calidad de abuelos viejos, son considerados literalmente como los progenitores de los Sonqo (Allen 1982, pp. 183-185). Sin embargo, los machula se confunden con los machu, una raza de gigantes malignos a quienes se les atribuye la construcción de las ch'ullpa en la edad de la luna, antes de que fueran destruidas por Taytanchis ( " nuestro padre ») cuando creó el sol. Sus huesos, manantiales y vientos causan sobre los simples mortales el efecto opuesto al de sus pares. En efecto, los machu viven en el mismo cerro que los machula y ambos son seres que continúan ejerciendo su influencia sobre los vivos y forman parte de una misma categoría, la de "ancestro », que identifica al ayllu Sonqo como tal (ibid., pp. 183-186). En otra versión del mito se presenta a los machu como una raza de gigantes que vivían en una bella ciudad y estaban organizados de acuerdo con las mismas instituciones domésticas y políticas que los sonqueños conocen actualmente. A diferencia de ellos, sin embargo, se dice que los primeros sólo tenían tres tipos de papa: para comida, para semilla y para ch'uño (papa deshidratada) y no conocían el ají (Allen 1984, p. 155). En su etnografía posterior; Allen realiza una serie de precisiones que resultan importantes para una caracterización más completa de los ancestros, quienes no sólo son designados machu y machula, sino también machukuna (" viejos »), ñawpamachu (« viejos antiguos ») o ñawpakuma ( " antiguos »). Al momento del cataclismo ellos se avisaron acerca de la salida del sol - lo que denuncia su capacidad de hablar - y entre sus huesos calcinados se distinguen los del alcade varayoq (" el que tiene la vara ») - lo que demuestra la existencia de gobierno y jerarquía - y los de las madres con sus infantes en brazos - lo que sugiere un sentimiento de amor filial. Sin embargo, los hombres aseguran que los antiguos son envidiosos e incluso rencorosos hacia aquellos que los desplazaron de la tierra - y sobre quienes manifiestan su ira haciéndolos presa de enfermedades y penurias. De todos modos, en sus invocaciones sobre las hojas de coca, las palabras machukuna, ch'ullpakuna, machula aulanchis y Antaqaqa son 
intercambiables (Allen 2002, pp. 38-49) ${ }^{38}$. Cerca de Sonqo, en las tierras de los pastores de Chillihuani (distrito de Cusipata, Quispicanchi), existe una cueva que lleva el nombre de machu mach'ay ("cueva de los ancestros »). Cuentan los pastores que cuando Dios creó el sol, o quizás fueron dos soles de un color extraño, los machu corrieron a esconderse hacia la selva, los lagos de las montañas y las cuevas donde se conservan sus huesos (machutullu). Por entonces uno de los soles se extinguió permitiendo surgir así a la humanidad actual (Bolin 1998, pp. 22-23). En el momento del cataclismo el fuego, quizás hayan sido dos fuegos, quemó no sólo a los hombres sino también a sus ayllus (ibid., p. 206). Preguntados si sus ancestros siempre vivieron en Chillihuani, los pastores, sin poder especificar fechas, recuerdan que los abuelos de sus abuelos vinieron de la región Qolla, del área de Puno y del lago Titicaca (ibid., p. 203). Y, en efecto, muchas de las versiones del mito de los ch'ullpa proceden del Collasuyu.

Quizás convenga regresar a los chipaya a través de la lupa de Nathan Wachtel. Los ch'ullpa vivían únicamente de la caza y de la recolección y se cobijaban en grutas cubriendo sus cuerpos con hojas y pieles de animales (Wachtel 2001, p. 15). La edad de estos seres carecía de periodicidad y su sol era una luna siempre llena que mojaba con una luz pálida un mundo sin color. Cuando apareció, el sol estaba muy cerca de la faz de la tierra y fue alejándose de a poco, permitiendo a los ch'ullpa abandonar sus refugios acuáticos y acostumbrarse a las nuevas condiciones de vida (ibid., p. 209). Se alimentaban también de la quinua silvestre, que a su vez es el único remedio para contrarrestar la enfermedad de los ch'ullpa. Entre sus restos destacan las cabezas voladoras que escupen fuego a la hora del crepúsculo, tratándose de la especie más peligrosa relacionada con los seres que fueron condenados por cometer incesto (ibid., p. 210). Los ch'ullpa, que no comprendían su lengua (ibid., p. 213), se oponen a los aymara de la misma forma en que los seres acuáticos y nocturnos lo hacen a los terrestres y diurnos - los primeros fueron cazados y pescados por los segundos con el fin de darles nombres, bautizarlos y enseñarles las artes de la agricultura y la ganadería (ibid., p. 215). A pesar de estos atributos negativos, la concepción nativa (desde la perspectiva aymara) subraya el hecho de que el mundo de los muertos o de los ch'ullpa es el reverso del mundo de los hombres vivos, aludiendo de este modo a una contemporaneidad - en calidad de puchu («sobra ») los chipaya y otros grupos lacustres son descendientes de los ch'ullpa - que también es complementaria, constituyendo los grupos en cuestión el elemento de mediación (ibid., pp. 215-216) ${ }^{39}$. El grupo morato (o murato) del lago Poopó, por ejemplo, se dice descendiente de dos parejas de ch'ullpa, dos hombres y dos mujeres, que pudieron escapar del incendio (ibid., p. 234). De la misma manera, los indígenas quechuahablantes del ayllu macha del norte de Potosí explican el origen de su organización en mitades en los mismos términos que propone el mito. En el tiempo pre-solar no existían mitades sino sólo una división entre los sexos en virtud de la cual los hombres eran designados Mariano y las mujeres María 
- nombres asociados, respectivamente, con el « cóndor » y el « espíritu de las montañas », por un lado, y con « la rana » y las «fuentes de agua », por el otro (Platt 1986, p. 243). Si las vicuñas, las perdices y el ch'uño son las llamas, los pollos y las papas de los ch'ullpa (ibid.), ello los ubica en un mismo pie de igualdad con los apu - en calidad de roal y ñawpa fuente de sociabilidad - para quienes la naturaleza salvaje es doméstica (nota 28).

Entre las versiones más conspicuas del mito de los ch'ullpa se encuentra la registrada entre los pastores aymara del ayllu K'ulta (departamento de Oruro), al este del lago Poopó. El mito contrapone a los ch'ullpa con un viejo barbudo forastero llamado Tatala, a quien buscaron dar muerte porque ellos eran muchos y él uno solo. En su persecución, los ch'ullpa preguntaron a otras personas si habían visto al viejo y éstas, señalando las cenizas de un fuego de cocina, les hicieron creer que hacía tiempo había partido. El fin del relato es como siempre: la mayoría pereció bajo el calor sofocante del sol y otros pudieron huir hacia los lagos convirtiéndose en los ch'ullpa actuales (Dillon y Abercrombie 1988, pp. 55-56). Esta versión muestra dos cosas: primero, los ch'ullpa podían hablar y, segundo, en su tiempo existía el fuego para cocinar alimentos. Ahora bien, existe la posibilidad de que el fuego y la cocción de alimentos no fuera patrimonio de los ch'ullpa y sí de otros pueblos contemporáneos a ellos, pero con quienes podían comunicarse en su misma lengua ${ }^{40}$. El mito, como siempre en el altiplano, está relacionado con el origen de los pobladores chipaya y morato del lago Poopó, considerados cazadores (de aves marinas) y recolectores, así como también con el espíritu de los antiguos que, en calidad de ch'ullpa, son incapaces de procesar los alimentos cocidos ni tampoco digerirlos (ibid., p. 57). Esta ambigüedad en torno de los alimentos cocidos se traslada en el mito hacia otros dos planos. En primer lugar, como ya se ha advertido, la naturaleza salvaje no es sino doméstica en el layra timpu (" tiempo de la ch'ullpa ») o en el manxapacha (" el mundo de abajo o interior ») y, en este sentido, el proceso de domesticación de la naturaleza por los hombres los distancia, e incluso enfrenta, con aquellos seres poderosos que tienen acceso directo a ella (ibid., pp. 57-58, 63). En segundo lugar, estos seres poderosos - los ch'ullpa - no son considerados ancestros por los k'ulta, quienes prefieren identificarse como hijos de Tatala, de una manera, eso sí, ambivalente e incompleta (ibid., p. 60). Es preciso ampliar este punto.

El término supay, asociado comúnmente con el sentido de «diablo » o " demonio », pudo haber sido aplicado en tiempos precolombinos para designar una categoría de ancestro (Abercrombie 1998, p. 456) y, en la versión k'ulta del mito, conforma junto con ch'ullpa el par que se opone al par Tatala-Jesucristo. Es decir, la pareja supay-ch'ullpa podría detentar alguna noción de ancestralidad de no ser por el hecho de que ella está reservada a la unidad Tatala-Jesucrito (ibid., p. 118). Sin embargo, hay dos términos que están asociados con la pareja supay-ch'ullpa que desvirtúan una oposición radical entre ambos pares de opuestos. En primer lugar, el término layra, asociado al tiempo pre-solar, también 
significa « lugar de origen » y, en una acepción más amplia, hace referencia a los " ancestros más remotos en una genealogía », a partir de los cuales los individuos trazan sus vínculos con otros parientes y contabilizan los grados de prohibición matrimonial (ibid., p. 322). En segundo lugar, ch'ullpa también se asocia con lari que, además de designar al animal predador por excelencia en los Andes (el « zorro », atoq en quechua), en su forma lari lari refiere a la " gente de la puna que vive fuera de la ley » y, en calidad de lari o larita, a los " parientes del lado de la madre » en general y al « grupo dador de esposas » en particular (ibid., pp. 325, 368-369) ${ }^{41}$. Es decir, a pesar de que los $k^{\prime}$ ulta nieguen una ascendencia directa con respecto a los ch'ullpa, el universo semántico que rodea al término remite a cierta noción de ancestralidad - aquella expresada en los términos layra y lari o larita. La pregunta que formula Thomas Abercrombie acerca del problema en cuestión manifiesta toda la tensión que, en definitiva, trasmite: ¿cómo una historia que no se refiere a los ancestros humanos propiamente dichos puede dar cuenta de los orígenes de quienes la relatan? (ibid., p. 326) ${ }^{42}$.

Una de las descripciones más recientes sobre los ch'ullpa proviene de la comunidad Kalankira (ayllu Macha, norte de Potosí). El mito cuenta que antiguamente el mundo estaba habitado por una raza prehumana llamada ch'ullpa que carecían del arte del habla y cuya era es denominada amu timpu, o « tiempo del silencio », de la ausencia de discurso y meditación. La aparición del sol sobre la tierra no sólo significó la destrucción de estos seres sino también el pasaje del tiempo del silencio al Inka timpu, o « tiempo del Inca », quien dotó a la tierra de sonido y al hombre de la capacidad de hablar, bailar y ejecutar instrumentos musicales (Stobart 2006, pp. 40-41). Entre los rituales que se celebran en la región, destaca en el mes de septiembre el rinuwa, o « fiesta de renovación », cuyos tambores evocan el sonido de la destrucción de los ch'ullpa y el fin del tiempo del silencio (ibid., pp. 185-186). Durante la celebración, junto con los músicos que tocan tambores, quenas y kuntur pinkillu («flauta del cóndor» o pinkuyllu, "flauta larga »), se hallan grupos de jóvenes que profieren voces en falsete y hacen bromas constantes. Estos últimos reciben el nombre de monos o ch'unchu, aludiendo con ello a los selváticos incivilizados y al consecuente comportamiento desproporcionado que los danzantes adoptan durante la celebración asociándolos, en un mismo movimiento, a seres mitad hombre mitad mujer en consonancia con el sonido estridente de sus voces (ibid., pp. 187-189). No debería ser objeto de sorpresa tras la serie de contrastes expuestos hasta aquí que los chipaya de las villas Chipaya y Ayparavi tengan otra versión de los hechos, ya que se consideran a sí mismos descendientes legítimos de los ch'ullpa (Baumann 1981, p. 173) ${ }^{43}$. Entre la herencia dejada a sus descendientes, los chipaya atesoran los maizu, o zampoñas que se tocan de a dos, así como las melodías y las tonadas (wirsu ch'ullpa) que acompañan su ejecución (ibid., pp. 174, 177). Otro nombre con el que se conoce al maizu es el de chirihuana, y la danza que su melodía acompaña se llama baile chirihuano o sakny chirihuana (ejecutada principalmente durante las 
fiestas celebradas al patrón Santiago) (ibid., pp. 178, 201, 205). Los chiriguano, a quienes el mismo Métraux dedicó numerosas páginas, conforman un grupo o etnia de las tierras bajas localizado al pie de los Andes y en la periferia occidental del Gran Chaco (Bossert y Villar 2007) ${ }^{44}$.

Entre los pastores de la región del Ausangate (provincias de Canchis y Quispicanchi) el mito de los ch'ullpa está relacionado con otras manifestaciones y seres del « mundo-otro » con los que resulta difícil establecer límites - incluso semánticos - precisos. Los machula o machu, seres del tiempo pre-solar, detentan una serie de características que los hacen ambiguos (Ricard Lanata 2007, p. 117): fuente de animación y de vida, igual que los apu (ibid., p. 121), también son los causantes de enfermedades y calamidades, igual que los ch'ullpa (el mal del machu o machusqa, asociado a los ñawpa tullu - « hueso del ancestro »-también se conoce bajo el nombre de ch'ullpasqa) (ibid., pp. 181, 393-394). En el contexto del rito, los ch'unchu suelen encarnar la figura de los machu, pero también encarnan la figura del inca, ubicando a machu e inca en una misma línea conceptual (ibid., p. 265). Finalmente, machu también se asocia con apu, en la medida en que, en contextos precisos, ambos invocan una noción de ancestralidad (ibid., p. 457). Esta ambigüedad, e incluso tensión, no sólo alude a mundos o eras diferenciadas pero en íntima relación, sino que también se inserta en la humanidad misma de los individuos y su proceso de gestación, definiendo así su propio ser.

Precisamente, las concepciones macha (norte de Potosí) acerca de la formación de la persona vuelven a desplegarse sobre una serie de planos antagónicos que se resuelven, esencialmente, en el proceso de parto. Las almas ancestrales que residen en el inframundo deben insertarse en el vientre de la mujer con el fin de (igual que los machu) dar vida y animar al embrión que se encuentra en su interior (Platt 2001, p. 634). Esta asociación entre el feto y el ancestro pre-solar hace del primero un ser peligroso, agresivo e incluso diabólico, cuyo proceso de socialización se resuelve en las prácticas post-natales ${ }^{45}$. Pero las asociaciones no se restringen a esto. La luna ejerce una influencia directa en la fertilidad de las mujeres, sobre todo en los períodos de las lunas nuevas y viejas en los que el sol, al cubrirla, copula con ella (ibid., pp. 643-644). De igual manera, los fetos abortados (q'ara wawa o "bebé desnudo ») son por lo general enterrados, sin bautizar y sin nombre, en las quebradas que marcan los límites de los territorios del grupo, y continúan creciendo hasta adoptar el aspecto y comportamiento de ch'ullpa- seres pequeños y barbudos dotados de un hambre voraz ya que se les ha privado de la ingestión de sangre en el vientre materno (ibid., pp. 650, 652). Un embarazo sano que llega a su fin es indicado mediante un sonido onomatopéyico de fermentación que rememora el hervor de una sopa calentada sobre tres piedras (qalapari o qalapurqa), comida predilecta de los ch'ullpa (ibid., p. 653). En el momento del parto, el desprendimiento del niño del cordón umbilical se realiza mediante un tiesto ( $k^{\prime}$ analla), asociado a un fragmento de las ollas de los ch'ullpa (ibid., p. 658). Tras ello, el niño es envuelto con una faja (chumpi) a la manera de 
las pequeñas momias que se conservan, o conservaban, en las sepulturas epónimas (ibid., p. 663). Esta última descripción, además de remitir inexorablemente al comienzo de los tiempos, recuerda también la impresión que causaron sobre el sabio d'Orbigny los cadáveres envueltos en esteras de paja que observó en las tumbas del sitio Crucero, en la provincia de Carangas:

[...] dentro de esa envoltura estaba el cuerpo reseco en una posición acurrucada, con las rodillas sobre el estómago y los brazos alrededor de las piernas. Se diría que los antiguos quisieron dar al cuerpo la posición que tenía en el seno de la madre antes de nacer, como si la vecindad entre la cuna y la sepultura uniera los dos términos de la vida del hombre, recordándole que nace solamente para morir. (d’Orbigny 2002, p. 1672)

Hemos mencionado que el término ch'ullpa ha significado muchas cosas para diversas personas. El ámbito del mito propiamente dicho no está exento de esta pluralidad de sentidos. De acuerdo con el lugar y la época considerada, la palabra ch'ullpa se asocia con nociones tales como " tumba funeraria », " enterratorio », « momia », « hueso », « pueblo de los antepasados », " ancestro », « gentil », " hombre sin bautizar », " enfermedad », " hombre de la selva » o, en términos vernáculos, mach'ay, samay, lari, awki, machula, machu, ñawpa runakuna, ñawpa machu, soq'a (machu, paya, pukyo), machu wasi, q'eru machu, apu, machu inka, ch'unchu y ayllu ${ }^{46}$. Esta amplitud en la nomenclatura no es patrimonio exclusivo de los ch'ullpa, ya que también la comparte su propio destructor quien, asociado a la figura del « sol », también encarna las figuras de un « cometa encendido », una "lluvia de fuego », "Juan Rubio », un "viejo con bastón », un « viejo blanco barbudo », " Dios », y, en términos vernáculos, nina para, Roal, Tatala, Dios churi, Taytanchis, Tumupa, Viracocha, Inti Huayna Ccapac e Inkarri. Asimismo, los atributos multifacéticos que en principio definen los contornos y el carácter de los ch'ullpa, quedan en cierto modo entredichos por otros igualmente definitorios, desvirtuando de ese modo una asociación inequívoca con uno u otro de los personajes o seres que se agrupan en uno u otro de los conjuntos semánticos contrapuestos. En efecto, considerados en su conjunto, los mitos reseñados en las páginas precedentes relatan que los ch'ullpa habitaban un mundo oscuro, acuático y sin color, apenas alumbrado por la luz de la luna. A veces gigantes poderosos, a veces hombres diminutos y con barbas, son polígamos, incestuosos, ignorantes de las artes culinarias, de la ganadería y la agricultura e, incapaces de digerir los alimentos, apenas conocían el ají. Dementes y paganos, taciturnos y mezquinos, vagabundeaban desnudos sobre la faz de la tierra, no tenían nombres, no hablaban y sus voces gangosas apenas podían pronunciar correctamente las palabras. No sabían cantar y desconocían los instrumentos musicales. Incapaces de percibir cualquier tipo de periodicidad temporal, también ignoraban la organización en mitades y todo tipo de institución social. Y sin embargo, estos mismos mitos, considerados en su conjunto, cuentan que en calidad de consumidores de chicha, además del maíz, los ch'ullpa conocían tres tipos 
de papa, y sus rebaños contaban con alpacas. Poseedores de riquezas, eran esmerados ceramistas y tejedores, como lo demuestran los cacharros, los tiestos y los restos de telas conservados en sus sepulturas. Respetuosos de la jerarquía y la autoridad, entre sus miembros existían profetas y alcaldes, y sus pueblos, ubicados en las alturas de las montañas, se asemejan a los actuales en lo que respecta al funcionamiento de sus instituciones públicas y privadas. No sólo podían hablar y comunicarse entre sí y con extraños, sino que también componían melodías, tonadas y canciones que eran ejecutadas con instrumentos musicales de su propia manufactura. En definitiva, si bien el mito contrapone dos polos de sentido que, de manera encadenada, se expresan en los pares ch'ullpa-humanos, chipaya-aymara, ch'ullpalsupay-Tatala/Jesucristo, ch'unchu-q'ero, q'ero-Hatun Kuyo, ch'unchu-qhapaq qulla, qulla-qhiswa, llacuaz-huari, uma-urco, conquistado-conquistador, sacrificado-sacrificador, etc., muchos de los atributos asociados con el primer componente del primer eslabón (ch'ullpa) son característicos de los segundos de los componentes que conforman cada eslabón del resto de la cadena de sentido, impidiendo de ese modo trazar un límite preciso entre uno y los otros. Pero el mito no expresaría tanto una ambigüedad pendular en torno de elementos contrapuestos como, más bien, una insistencia en la incapacidad de concebirlos como tales, separadamente y de manera independiente. Tampoco se trata de un ejercicio intelectual que contrapone los opuestos de manera especular ya que, más bien, todo aquello que se predica de los ch'ullpa no sólo es predicado acerca del hombre sino que también remite a su propia condición. Para decirlo de manera un tanto elíptica, hay tanto de inhumano en los ch'ullpa como en aquellos que hablan, y piensan, acerca de ellos - y vice versa.

\section{LOS CH'ULLPA EN MARCAPATA}

En el atardecer de un día de julio de 2005, sobre un promontorio desde el cual se visualiza el caserío de Laccowasi (sector Lacco, ayllu Collana), sus inmediaciones y el perfil sombrío de las montañas circundantes, preguntado acerca de la existencia de qhapaq ñan (« camino real » o « camino inca ») en Marcapata, el señor Luis Huayhua Condemaita respondió que el único camino antiguo que conocía en la región era aquél construido por los ch'ullpa. A ello agregó:

LHC: Antes, dice, que por esta zona vivían los ch'ullpa. Por estas rectas, en esas cuevas, sus huesos, sus calaveras, bastante... te puedo mostrar. Te puedo llevar a Kara Kara, a Llaulli Huayq'o, en ahí está, bastante ch'ullpa, el hueso de los ch'ullpa. Entonces, esos andenes, esos canchones... o sea a la tierra lo mejoraron, pues, los ch'ullpa, por esta zona. Entonces... ¿Cómo era el comentario? Dice que pues antes no había sol, sólo ellos tenían la luna no más. Entonces, según ellos, comentaban pues, posteriormente dice que va a haber, va a salir awqaysunkha, que es el sol. « Habrá awqaysunkha. Bonito será. Habrá el awqaysunkha. Nos va a quemar », así dijeron, « nos va a quemar ». Entonces, 
construyeron su casa. « De este lado el sol va a salir. De este lado de la puesta del sol». No del lado por donde sale el sol, a lo contrario construyeron sus casas. Entonces no pasó así. Por el Este salió el sol y lo quemó. Construyeron todos con puertas hacia ese lado. Todas las puertas hacia la salida del sol. Entonces los quemó. Todos sus huesos están amontonados [...]

[...] ¿Y por qué decimos ch'ullpa? Ellos eran, pues, medio envidiosos. Porque a sus mushk'as [morteros], maranes [maran, batán grande, piedra plana cuadrangular para moler granos], todas sus cosas que utilizaban, que sería para la generación posterior, para los hombres que van a venir posteriormente, " mejor destrozamos ", lo destrozaron completamente, lo rompieron. Como sea tenían que romper. Así lo dejaron. Entonces sus qollotas [piedra redonda para moler], sus marames, sus mushk'as, siempre hoy día encontramos, rotos. Hoy unas raras veces encontramos sanitos. No puedes encontrar fácilmente, este, así, entero. Así es. A sus illaqo [illaku, lisas], a sus papas, a su maíz, los echaron a los pedregales, a los ríos. Y no... Final todo el tiempo, creían que en cada año, en esta fecha, se iba a finalizar el tiempo, el mundo, ¿ya? ¿Te das cuenta? Entonces, como sabían exactamente el final del tiempo, lo echaron, para que no quedara para el resto que viene. Entonces por ahí. Entonces... No, fue así. Duró más de siete años todavía, dicen, según la historia. Murieron de hambre, hasta a sus hijos comieron [...]

[...] Por toda la zona de Marcapata hay bastantes restos de los ch'ullpa. Y siempre en aquí vivieron. Siempre vivían acá. Entonces, eso ahora está. Están creciendo en los pedregales, ch'ullpa papa, ch'ullpa añu, ch'ullpa illaqo. Las papas de los machulas está habiendo. Entonces esa papita que habían echado ha crecido. Cuando tú quieras yo te voy a hacer conocer. Pero ahora ya está floreciendo. Siempre papa pues crece, florece. Pero produce muy poquitito. Para que no desaparezca la semilla. En allí está creciendo papa t'uruña. También hay illaqo, añu en los roquedales. Entonces el tiempo no se terminó. Entonces te voy a avisar la historia de una ch'ullpa. Dice que se habían cocinado. Cualquier cosita para que puedan comer posiblemente encontraron todavía. Se cocinaron. Entonces en la ch'ullpa a su hijo ha hecho matar. Dicen que lo han podido. "¿Dónde está el cucharón de palo?», diciendo, para que puedan darse de comer. Ya, «¿Dónde está cucharón para servirnos? ». De un momento a otro el niño habló, « Está encima del hueco », diciendo, "Está encima del hueco ». Y había estado vivo. Entonces con la piedra del mortero lo [pusieron] para que se muera. Así hacían los ch'ullpa $[\ldots]$

[...] Dice pues a sus hijos lo mataron, incluso lo comieron, porque no había qué comer. Entonces, dice pues, una familia, un día, completamente estaba matando a sus hijos. Como sea para sobrevivir ellos habrán cocinado algo, pues. Entonces estaba envuelto en una frazada con q'aqlakara [pellejo de oveja sin la lana]. Entonces hicieron, pues, seguramente hayan cocinado y estaban listos para servirlos. Entonces el chiquito dice que habló, pues, "¿Dónde está el cucharón? ». En quechua se llama wislla, hecho a base de madera, de k'ullu. Entonces, "Allí está. Está encima de ese hueco ». Se amarraron, taparon con maran, pesante, de piedra, pues. Murió, pues, el chico. Así es. Es todo [...]

[...] Hay muchas historias de los ch'ullpa. Hay varios temas de los ch'ullpa. Mira, acá tienes, caminos, dónde vivían, qué cosas hacían los ch'ullpa. Ch'ullpa, principalmente 
dedicaron por esta zona, por esta zona de Marcapata, a arreglar los terrenos para trabajar. En tiempo de ch'ullpa todos asistían, todos o nadies. Al qella [ocioso, perezoso] lo metieron al cerco, como pago, así vivo, al qella, así. Tenían que trabajar duro y parejo. Eso bastante hay, pues, los andenes que han hecho los ch'ullpa por acá [...]

PFS: ¿Pero quedan sus cosas todavía?

LHC: Sí, sí, bastante. Sus ropas de ch'ullpa, frazadas, mantas, siempre el color castaño, siempre. Y lloq'e, izquierdo, zurdo. Todos hilados hacia el lado izquierdo. No puedes encontrar paña [derecho], como el tiempo de ahora, no. En un lugar llamado Karkari había todavía las chusis [frazadas tejidas a mano] de los ch'ullpa. Seguramente, pues, así ellos aprendieron a hilar. Todo hacia el lado izquierdo, siempre hacia el lado izquierdo. No hay el lado derecho. Eso es como para reírse. Entonces está el camino por el que ellos han caminado. Seguramente ellos se hicieron su camino. Bien con las piedras ellos construyeron. Bonito está lo que ellos han caminado. En aquellos lugares en todas formas están sus casas. Allá abajito nosotros decimos Iglesia Kancha, Iglesia Kancha. Los ch'ullpa como iglesia construyeron. ¿Qué cosa todavía no habrán hecho ellos? [...] De piedra. Pared ancha. Ahora poquitito no más está todavía, está todavía. [...] Es que haciendo esa carretera lo han destrozado, ese tractor. Antes estaba entero. Vieja, vieja, vieja no más ya. Pero todavía estaba bien parado, de pura piedra, de pura piedra pues. Ya no hay las ch'ullpa. Únicamente en las cuevas están sus huesos, sus cabezas. Solamente sus huesos no más están. En los pedregales, en las cuevas, en las grandes cuevas pues. Algunas veces también en las cuevas pequeñas. Algunas veces están todavía los huesos con grasa, sus huesos también. (Versión en quechua y castellano de Luis Huayhua Condemaita, 35 años, sector Lacco, ayllu Collana, Marcapata, $10 / 7 / 2005)^{47}$

En Marcapata no hemos visto torres funerarias del tipo descrito en el altiplano puneño y boliviano. Sí existen cuevas (mach'ay) ubicadas en la cima de los cerros, por lo general de difícil acceso, que contienen restos óseos, trozos de telas y piezas de cerámica asociados a las casas y tumbas de los ch'ullpa. Además de los sitios mencionados en el relato anterior (Kara Kara, Llaulli Huayq'o y Karkari, que no hemos visitado), hemos podido registrar dos cuevas de dicha naturaleza en el territorio del sector Ch'umpi del ayllu Collana, cuyos nombres son Kallinsaya (" calle de la saya », caserío de Thunkus) y Aya Qaqa o Ch'ullpa Mach'ay (« roca del muerto » o « cueva del ch'ullpa», caserío Ch'umpipata). De todos modos, el relato vincula directamente las cuevas en cuestión - y también los restos de una construcción de piedra y pared ancha denominados Iglesia Kancha - con los restos de los ch'ullpa y el mito correspondiente ${ }^{48}$. Aunque explícito de por sí, el relato presenta una riqueza de contenidos sobre los que es valioso detenerse. Primeramente, es notable la industria que se les atribuye a los ch'ullpa, hacedores no sólo de caminos sino también creadores de los terrenos y la andenería para la siembra de diversas clases de papas, maíz, lisas, añu, etc., en las laderas de las montañas. Esta industria se traduce en una moral del trabajo en la que el ocioso era presa de los más severos castigos y vejaciones. Asimismo, 
estaban dotados de instrumentos para el procesamiento e ingestión de los alimentos tales como morteros, batanes, piedras de moler y cucharones. Conocían también el arte de la textilería y podían hablar - como lo demuestran las dos referencias en el relato a la búsqueda del cucharón por parte de los padres antes de comer a su hijo, y a la manera en que los ch'ullpa se advierten entre sí acerca de la salida del sol. También poseían una noción de temporalidad y periodicidad, como lo confirma el hecho de que cada año, en una fecha determinada, esperaban el fin del tiempo. Y sin embargo, estos atributos positivos son contrapuestos a los trazos negativos que también delinean parte de su carácter. Los ch'ullpa son envidiosos, pero envidiosos ante la humanidad venidera, a quien le niegan el acceso a sus riquezas prefiriendo destruirlas en lugar de legarlas ${ }^{49}$. De igual modo, de ellos se predica la práctica de la antropofagia; pero ello, en rigor, resulta más bien excepcional y se circunscribe al momento de su destrucción, en el que prácticamente no tienen nada que comer. Incluso el relato no deja de manifestar un giro dramático cuando los padres, al buscar un cucharón, escuchan la voz de su propio hijo indicándoles el lugar en que se encuentra. Si bien tejedores consumados, los restos de sus tejidos confirman que hilaban de izquierda a derecha, es decir de manera inversa a la práctica contemporánea ${ }^{50}$. Finalmente, aunque eran capaces de hablar y comunicarse entre sí, no conocían la palabra sol (inti) a quien, cuando se levantó sobre la faz de la tierra, lo designaron awqaysunkha. Este término detenta dos sentidos relacionados. Literalmente significa " mi enemigo barbudo", coincidiendo así con muchos de los personajes a quienes se les atribuye su destrucción. Pero también se trata de una representación figurativa del sol, cuyos rayos están asociados metonímicamente con barbas (sunkha) rubias o blancas ${ }^{51}$. Aunque todas las versiones locales del mito coinciden en sus aspectos generales con esta primera caracterización, ellas contienen a su vez otros elementos que enriquecen aún más algunos de sus aspectos.

LMS: Ch'ullpa son pues de los antiguos. Antes de los incas, pues [...] Es que los ch'ullpa vivían antes. No había sol. Marcapata en este Lacco estaba. En Lacco había ch'ullpa, bastante, vivían en todo sitio. Existen casas en aquí, en allá, en diferentes sitios, las casas en que ellos habían vivido están [...] Ellos trabajaban la papa, para poder comer. Trabajaban la papa, también hacían la oca, trabajaban la chacra. Entonces ya sabían ellos lo que el padre sol iba a salir. Entonces había uno que era el jefe de ellos. Entonces ellos dijeron que va a salir el awqaysunkha. Al sol lo llamaban diciendo awqaysunkha. "El awqaysunkha va a salir, ahora a todos nos va a secar para siempre ", diciendo. Entonces, sin darse cuenta no más, pasó un mes. Entonces esto seguro no era [época] para que ellos puedan morir. Entonces ellos todas sus cosas, así como a esos lugares pedregosos, su dinero a las pampas, sus papas también echaron para siempre a esos lugares pedregosos. A todo sitio distribuyeron para siempre lo que habían trabajado. Entonces no quisieron dejar para la gente de este tiempo. Todas las cosas escondieron ellos. « Todo nuestro dinero nos lo vamos a esconder ». O sea... esos batanes para poder moler ají eran de piedra. Eran tan lindos así como los platos. También había batanes para que ellos pudieran moler maices. Esas cosas lo rompieron para siempre. Empeza- 
ron a romper con los combos. Y una parte que no pudieron romper enterraron debajo de la tierra, así como aquí debajo de esta pampa. También sus platas enterraron también debajo de la pampa. Ya entonces después ellos no murieron. No murieron pero siguieron en el mismo sitio. Existieron todavía por mucho tiempo. Casi se comieron unos a otros. Definitivamente no encontraron comida. No había comida. Entonces unos a otros... A sus hijos también ya no les servían comida, sólo ellos nomás ya comieron. También ya no fueron a recoger, a escarbar, la papa araqa [papa silvestre]. Actualmente está creciendo mucho ese tipo de papa araqa, sigue creciendo. Ese tipo de papa en una mata produce dos papitas no más. Amargoso es, no se puede comer. Entonces de esta forma, después de mucho tiempo ya, lo que ellos llamaban awqaysunkha, el sol, salió. Ya, cuando el sol salió ellos se fueron para siempre. Se ocultaron así como en aquellas cuevas. En alli, en el mismo sitio, ellos se secaron. El sol a ellos los hizo secar [...].

[...] Entonces así eran ellos. Hasta ahora también sus papas siguen creciendo, así como en esas laderas sigue creciendo. La papa, lo que trabajan, está creciendo. Sigue creciendo. Esas papas son antiguas. Todavía eso, esa papa antigua nosotros también seguimos trabajando. Son harinosas, ricas papas son esas [...] Yo sigo trabajando mucho. Mucha variedad de papas hay. Se llama havichu, moroña, churuspi. Esas papas antiguas de los incas todavía. Esas papas buenas son [...] Yo ahora sigo trabajando en mi chacra. Ahora en mi casa sigo guardando. Trabajando así de esta forma ellos murieron. Algunos de ellos se entraron para siempre por el agua, por el agua del río hasta la selva. Algunos se escaparon. Esos son los ch'unchu. Los ch'unchu de esta parte son nativos. Nativos que viven en la selva alta. Estos son una parte de ellos [...] A través del agua llegaron a la selva. Entonces en los lugares despoblados en el monte empezaron a vivir. Pero nada conocían. Ellos no tenían ropa, estaban desnudos nomás. Ellos no conocían la ropa. Entonces abrigándose con las hojas del plátano estaban. A sus hijos también con eso nomás les criaron. Pescaban con flechas. Caminaban. Ellos tenían unas flechas especiales para poder cazar [...] Los chu'llpas ahora son esos. Ahora los llamados ch'unchu en abajo. Ahora ya no hay creo. Dónde no más ya estarán poco [...] Entonces así eran. En esa parte, en abajo, están muchos nativos. Otras partes dónde todavía estarán. Ahora actualmente el alcalde de Marcapata, él todavía sabe la vida de esos. Él sabe bien de la vida de los ch'unchu [...] Eso que llaman ayawaska esos ch'unchu, oraciones le enseñan también [al alcalde]. Eso sabe ese. Sabe curar a los que están enfermos. (Versión en quechua de Luis Monroe Sanga, 46 años, sector Lacco, ayllu Collana, Marcapata, 14/7/2005)

En este segundo relato se explicitan tres cuestiones importantes. En primer lugar, existe una asociación entre, por un lado, los ch'ullpa, los « antiguos» anteriores a los incas y un tipo de papa silvestre, amarga y no comestible y, por el otro, los mismos « antiguos », varios tipos de papas comestibles que continúan cultivándose y que provienen del tiempo de los incas - dificultándose así una delimitación clara entre incas, antiguos y ch'ullpa. En segundo lugar, es a un " jefe » a quienes sus súbditos informan sobre la llegada del " enemigo barbudo ", lo que confirma nuevamente el reconocimiento de jerarquía y orden social. De todos modos, y en tercer lugar, la afirmación de que los ch'unchu 
contemporáneos son los descendientes de aquellos antiguos que pudieron evitar morir calcinados escapándose por las aguas de los ríos en dirección a la selva, pone a unos y otros en un mismo pie de igualdad disociando, así, cualquier tipo de identificación inmediata de los ch'ullpa con los seres humanos. Incivilizados, desnudos, vagabundos, cazadores, brujos y hechiceros, los ch'unchu encarnan en su propia humanidad aquella otra que, desde esta perspectiva, no puede considerarse como tal. Debido a la ubicación geográfica del territorio de Marcapata al oriente del departamento del Cusco - antesala del piedemonte amazónico en la que confluyen elementos quechua, aymara y de las así denominadas «tierras bajas »- es preciso hacer aquí una digresión.

En el contexto marcapateño, y del Ausangate, el ch'unchu resulta el arquetipo del uro-chipaya-morato del altiplano. Pareciera como si el mito se adecuase a las condiciones ecológicas locales reservando la condición « ch'ullparia » a aquellas poblaciones que viven arrinconadas o en relativo aislamiento en regiones húmedas que, aunque diferentes a sus pares lacustres, son igualmente acuáticas. El surgimiento de torres funerarias en el altiplano (" intermedio tardío ») parece coincidir con la era de los acuaruna ("guerreros» o awqaruna, "hombres enemigos ») en la que pastores migrantes de lengua aymara hicieron retroceder de sus lugares de origen a los pobladores uro y de lengua pukina hacia las regiones húmedas de los lagos y los valles tropicales (Renard Casevitz et al. 1988, p. 33). La percepción aymara sobre los segundos es reproducida en la percepción de los incas sobre los ch'unchu, las poblaciones selváticas del Antisuyu. Sin embargo, desde una perspectiva espacial y temporal, los anti son seres ambiguos. Si bien ocupan una región que en sí misma constituye un límite para el avance inca y está asociada con la noche y la oscuridad, su cercanía al Levante se vincula con la salida del sol, fuente de vida, así como su carácter acuático y húmedo es fuente de lluvia y abundancia vegetal y mineral (ibid., p. 49). Igualmente, estos descendientes de una humanidad primordial que pereció con la salida del sol todavía conservan sus poderes a la manera de grandes antepasados, entre los que se destacan su condición de magos y brujos consumados (ibid., p. 93). Junto con estas representaciones de orden general, la etnohistoria también enseña que estas poblaciones trabaron una serie de vínculos a lo largo de una ecología evocada por el mismo mito. Se sabe que indios ch'unchu (araona) de la provincia de Carabaya - límite oriental de Marcapata - llevaban al Cusco, en calidad de tributarios del Inca, importantes cantidades de oro, plata, plumas y riquezas de la tierra al igual que sus pares de Opatari, localizados en el valle de Kosñipata (Paucartambo), quienes llegados al Cusco fueron ejecutados y enterrados junto con su oro en el monte Pachatusán (nombre del apu principal marcapateño) (ibid., pp. 72, 92). En sus incursiones hacia el Antisuyu, los incas parecen haber seguido una ruta que, desde el Cusco, descendía por Paucartambo en dirección al Alto Madre de Dios y los ríos Marcapata e Inambari en dirección al sur atravesando, y a veces arrasando, los territorios controlados por los indios Cuyo, establecidos en la 
provincia de Quispicanchi, entre Paucartambo y Carabaya (ibid., pp. 105-107, $122,131)$. Su ubicación estratégica en relación con el acceso a los ricos cocales no sólo ejerció una fuerte atracción sobre los incas - como atestiguan los caminos de altura que unieron los valles de Paucartambo y los de las cabeceras del Madre de Dios (ibid., p. 125) - sino también sobre los pastores y «trajinantes » quienes, durante el período colonial, sino antes, transitaban una suerte de corredor que vinculaba el oriente cusqueño adyacente al Antisuyu con los territorios sureños del Collasuyu (Ricard Lanata 2007, pp. 37-39; Glave 1989, pp. 66-69). Independientemente del problema de la identificación precisa del grupo Cuyo - ise trataría de poblaciones de origen aymara tal y como lo sugirió Nordenskiöld a comienzos del siglo pasado? - las eventuales relaciones entre los incas y los ch'unchu parecen haber estado mediatizadas por la presencia de poblaciones no-incas cuyos territorios, íntimamente ligados al de los ch'unchu, cuentan con ch'ullpa - ¿se trataría de los antepasados mismos de las poblaciones que, como la marcapateña, ocupan actualmente la región? ${ }^{52}$

En la versión anterior del mito marcapateño se menciona que el alcalde de Marcapata, autoridad que ocupa el pináculo de la jerarquía distrital, es un conocedor de las artes de los ch'unchu quienes, además de oraciones, le enseñaron las virtudes curativas del ayawaska. En ocasión de alguna calamidad, los marcapateños suelen organizar pequeñas comitivas que se dirigen a la ceja de selva con el fin de consumir este alucinógeno bajo las directrices de un chamán local con el fin de identificar la causa del mal ${ }^{53}$. En otra versión del mito se vuelven a apreciar los atributos positivos de los ch'ullpa y se especifica que los ch'unchu, sus descendientes, son expertos en el arte de leer la hoja de coca:

LFHB: Los ch'ullpa antes eran hombres. En el tiempo de la luna, solamente luna había. En ese tiempo trabajaban la papa, también el maíz, también las lisas, oca, añu, todo. Siempre habían sus vacas, también sus caballos, sus llamas. No había alpaca. Sólo eso había. Solamente la noche trabajaban. Sus papas daban frutos solamente tres. Una para semilla, una para ch'uñu, también uno para papa. Los ch'ullpa decían... Antes no había sol. Sólo en la noche, sólo en la luna estaban. Y entonces ellos fueron a la cueva a ocultarse. Al sol ellos le decían, " Awqaysunkha va a salir de allá hacia acá », diciendo. Ellos a las cuevas se fueron a esconder. De este lado iba a salir el sol. Y entonces fueron a esconderse a ese lado. Entonces el sol salió desde el lado en que se habían escondido. Desde entonces ellos se han secado en las cuevas. Se han secado. Y algunos por el agua se entraron hacia el monte, a la selva. Y entonces algunos en allí todavía están vivos hasta ahora. Ahora están ch'unchu, están ch'unchu. No se encuentra con la gente. Dice que esos saben mirar la coca, matar a la gente. Ahora en aquí están todavía los ch'ullpa secados. Todavía continúan sus huesos, sus cabezas también. En Chumpi ahora están todos. Ahora están muertos no más ya, huesos no más ya. Secados por el sol. (Versión en quechua de Luis Francisco Huaracayo Bedoya, 35 años, sector Chumpi, ayllu Collana, Marcapata, 22/7/2005)

Este relato reconoce, al igual que los runakuna de Sonqo, que los ch'ullpa clasificaban sus papas con tres finalidades: para comer, para semilla y para 
ch'uño. Además, la afirmación de que los selváticos son expertos en la lectura de la hoja de coca los pone en un mismo pie de igualdad con los humanos, o al menos con una clase peculiar de ellos, el altomisayuq o el chamán que tiene la capacidad de comunicarse con los apu. Sin embargo, esta asociación se ve cuestionada por otros atributos otorgados a los ch'unchu:

PFS: ¿Y los ch'ullpa se fueron para el lado de la selva o algo así?

MQR: No creo. Por gusto algunos han dicho que han escapado por el río. Dice que pudo haber entrado por el agua, unas cuantas personas. Eran, parte de abajo, en la selva, puros nativos. Ch'unchu no más, nativos no más eran ellos. Ahora también, nativos civilizados hay, hay todavía.

PFS: ¿Hay, o hubo antes, o te contaron antes en Marcapata alguna relación entre la gente que vivía acá y los ch'unchu de abajo?

MQR: Eso más bien no sé. No se sabe. De repente ellos eran salvajes o de repente muy lisos eran esos, muy lisos de repente parte de arriba. Entonces mejor no acercaban. Si escapaba el otro en parte ch'unchu y... ch'ullpa también se escapaban. Así era parece. Porque otra clase de comida el ch'unchu come, y otra clase de comida come así. No había comprensión. No eran civilizados. Más salvajes eran ch'unchu. Porque eran de montaña, con flechas, con todo, lisos eran. Esos no tienen nada. Eran humanos, así, pero simples, nada más. No tienen defensa, nada, no sabían [...]. (Fragmento de versión en castellano de Martín Quispe Rojas, 29 años, sector Chumpi, ayllu Collana, Marcapata, 1/8/2005)

Esos atributos de los ch'unchu, descendientes de los ch'ullpa, parecerían quedar en cierto modo entredicho en otros relatos sobre los ch'ullpa, en los que vuelven a subrayarse su esmero en el trabajo así como también su rectitud moral:

SQB: Sí, sí, siempre está. Eso también yo he visto. De eso su nombre es Santo Domingo, es un cerro. En allí están los ch'ullpa, pero no sé. Pero antes murieron ellos cuando salió el sol. Ellos se fueron. Antes no había sol. En el tiempo de los ch'ullpa no había sol. Solamente era killa, luna. Eso no más era. En estos lugares vivieron. Ellos hicieron la chacra. ¿Qué cosas? Papa, oca, lisas, añu, esas cosas ellos trabajaron [...] En aquí la papa antigua está todavía, en aquí. El llamado ch'ullpa papa está todavía en aquí. Habían papas t'uruña, maqt'a lomo, k'usi, leqe chaki, q'olla. Esas variedades hicieron [...].

PFS: Yendo a Huayllapata vi una piedra grande. Está como una puerta. Avísame esa historia.

SQB: Eso era llamado cárcel Qaqa [qaqa, cueva]. Era la cárcel Qaqa. Dice que eso había sido cárcel. Su cárcel de los ch'ullpa. A ese lugar mutuamente se enviaban. En allí mutuamente se cerraban. Fueron a merecer el castigo. Y cuando tenían muchos pecados los trajeron hacia la pared. Hacia la pared los hacían colgar vivos. Vivos, vivos en aquellas paredes están, hacia allí. A los hombres que tenían muchos pecados en medio de las paredes los pusieron. Y para que nunca jamás salgan, para que se mueran, a su encima les ponían piedras. Aquella cárcel de piedra su nombre es Qaqa. Eso, eso era su cárcel en aquellos antiguos tiempos [...]. (Fragmento de versión en quechua de Santos Quispe Bedoya, 38 años, sector Chumpi, ayllu Collana, Marcapata, 5/9/2005) 
Además de especificar una nueva serie de papas cultivadas por los ch'ullpa, el relato amplía aquella observación registrada en la primera versión acerca del tratamiento que recibían los ociosos y los individuos que se negaban a cumplir con los trabajos estipulados. En efecto, sobre el camino que se dirige hacia la parte más elevada cercana a los nevados del sector Chumpi, se erige una roca de dimensiones extraordinarias que es asociada con una cárcel a donde los ch'ullpa enviaban a los pecadores, quienes sufrían los más severos tratamientos.

Conocedores y poseedores de plata, oro y dinero, los ch'ullpa prefirieron esconderlos al momento de la salida del sol antes que entregarlos a los humanos, sobre quienes ejercen una serie de males y enfermedades llegando incluso a, literalmente, enloquecerlos:

SSL: Antes, antes. O sea, había, existe. Y también hay todavía restos de ellos. Conocían también la plata. Es como la libra esterlina pero q'allo [tajado, cortado], en tres esquinas así. Eso cortaban, pagaban de algo, entre ellos. Hacían también compra, o también trueque [...] Oro chancado no más en tres esquinas, así. Ellos, antes de morir, lo han ocultado. Ese tapado, de los ch'ullpa. De ahí también tapado de los incas, de ahí también tapado de los españoles hay. Sí, sí, hay [...].

[...] Eso... existe los ch' ullpa. Te agarra. No te agarra así sino... Te introduce su... de repente su antimonio, ¿qué será? Pero te seca y así, un ratito, un ratito mueres. Pero ahora ya no hay eso de que te agarre el ch'ullpa. Ya no, ya no ya, ya no tiene valor, poco a poco está perdiendo su valor el ch'ullpa. Antes sí, hasta en huesos, rompías el hueso, había venitas de sangre en allí, como dentro del hueso. Vivos, vivos [...] A través del tiempo también, también como la piedra, igualito se gasta, también ellos también están gastándose ya. Ya no tienen tanto valor. Antes esos huesos caminaban. Se convertían en gente y llegaban, así, a mujeres que estaban solas, se parecían a... se convertían en su esposo. Y llegaban, y de allí hasta se acostaban. Para qué no más ya, esa mujer ya no tiene vida. Dura tres, dos meses, enflaqueciendo muere. Ch'ullpasqa. Y para eso la medicina... Si ves el hueso, encuentras, lo chancas, tomas y sanó [...] Por decir este hueso, un hueso, ¿no es cierto? Buscas ese hueso, en las cuevas. Entonces traes ese hueso, los martajas, y esito lo tomas, lo hacen tomar a la enferma. Y con eso se sana. Pero si es otro hueso no lo sana tampoco [...]. (Fragmento de versión en castellano de Susano Sarmiento Loayza, 50 años, pueblo de Marcapata, 13/7/2005)

En otra versión del mito se vuelve a mencionar el dinero de los ch'ullpa y los males que ejercieron sobre la humanidad venidera:

DQB: De esta forma se habían secado. El sol a los ch'ullpa los había hecho secar rápido. Sus dineros también no se sabe a dónde habrán ocultado. Antiguamente los ch'ullpa habían sido envidiosos. Alguito de ellos, sus cositas buenas también, los habían roto. Sus ollitas también, sus morteritos también de la mitad lo habían roto. Hasta sus comidas también a los roquedales los habían echado. Por todo sitio lo habían echado. En esa forma su vida de ellos se ha terminado, de esos ch'ullpa. Y después vivieron los ch'ullpa. Los ch'ullpa, a las generaciones posteriores, enloqueciéndolos no más, los habían matado. Ahora también están todavía por algunos lugares, pero ya no es mucha 
cantidad. Así esos habían sido. Los ch'ullpa dice habían hecho paredes. En las partes altas paredes de los ch'ullpa siempre están. Entonces seguramente siempre hicieron. Chacra también dice habian trabajado. Papa, añu, oca, igual. Ellos vivieron en las cuevas. Hacia el lado de Puiqa sus casitas también están. En aquí abajo no hay. Sus casitas habían sido de piedra, pequeñitas, redondeaditas. Yo no voy hacia Lacco. De repente habrá. En Sahuancay siempre hay. Seguramente están en todo sitio. En Puiqa tienen su casa. Desde Wayllaru hacia Palqeya está yendo hacia arriba. En Puiqa están hechas casitas, no son sólo cuevas [...]. (Fragmento de versión en quechua de Diómedes Quispe Bedoya, 42 años, sector Chumpi, ayllu Collana, Marcapata, 8/9/2005)

Los ch'ullpa supieron concebir las virtudes del oro y de la plata y mediante su acuñación crearon una especie de moneda. Además, y como hemos observado en varias oportunidades, sus huesos constituyen la fuente de curación para los males y enfermedades que ellos mismos inflingen a los mortales. Los huesos y el dinero detentan evidentemente un carácter ambiguo relacionado con la misma condición de los seres que los encarnan. Es decir, aunque fuente de curación, los huesos de los ch'ullpa son decididamente peligrosos, al igual que sus dineros y riquezas, a las que se puede acceder a través de la más estricta observancia ritual ${ }^{54}$.

Esta serie de relatos marcapateños se adecua al corpus mitológico comentado en el apartado anterior tanto en sus detalles puntuales y en sus lineamientos generales. Si bien los ch'ullpa parecieran encarnar todo aquello que no es humano y que resulta ajeno al universo de lo social, lo cierto es que muchas de sus características reconocen visiblemente ambas esferas - no sin ciertas interrupciones, es justo admitir. Pareciera como si los runakuna de Marcapata, al negarles toda condición humana, cuando se detienen en precisar los atributos de los ch'ullpa no pueden evitar reconocer en ellos características propiamente humanas y asignar una condición no humana a otro universo, el de la selva y los indios ch'unchu - lo que no deja tampoco de presentar imprecisiones dadas las percepciones también ambiguas sobre ellos. Esta relatividad en la concepción de la condición humana se encuentra en el corazón del mito chipaya y, creemos también, en el resto de los mitos relativos a los seres del tiempo pre-solar. El corpus marcapateño pareciera acentuarla aún más. En un número significativo de los mitos del área aymara reseñados en la sección anterior se considera a los chipaya como descendientes de los ch'ullpa, y estos últimos son concebidos como sus antepasados - incluso por los mismos chipaya. El mito marcapateño, por su parte, pareciera desplegarse sobre dos planos en uno de los cuales se contrasta a los humanos con los ch'ullpa-ch'unchu - los ch'unchu descendientes de los ch'ullpa - y en el otro a los ch'unchu con los humanos-ch'ullpa - los ch'ullpa ancestros de los humanos-, presentándose así una instancia de reconciliación entre humanos y ch'ullpa. Efectivamente, una de las versiones es explícita al respecto:

CCM: Ch'ullpa antiguo inca. Eso es Inca Pacha Kuraka. Ellos son incas, ellos son los llamados Pacha Kuraka Inca, son llamados. Por eso ellos son awki. Hacia ellos debemos 
ofrendar, diciendo. « Mi abuelo Pacha Kuraka, acuérdate de mi, para estos tus hijos, para estos tus nietos, oro, plata, herencia envíame tu a mi ». Él acostumbra comer con contribución, con patente. Yo acostumbraba decirle todo, "Envíame, acuérdate de mi », diciendo, debemos decir al awki. Entonces esos son hombres del tiempo ch'ullpa. Todavía no era tiempo de papá Dios. Cuando el hijo de Dios no estaba allí esos hombres había. Entonces ellos caminaron sólo en esa luna, eran. Entonces sólo en esos cerros altos hicieron sus casas. Porque las pampas eran limbu [limbo, oscuro], no hicieron en debajo de la tierra. Entonces, cuando ellos se sequen, cuando todavía no haya sol, para que ellos puedan salirse. Diciendo « El sol nos va a secar », hacia las cuevas se entraron para siempre, a los manantiales para siempre. Algunos se entraron para siempre hacia la yunka [selva]. Esos machulas son hombres de ese tiempo. Entonces algunos enteros no más están en los pedregales, en las cuevas [...] Eso es machula. Antes de Cristo todavía habían pues esas gentes. Así pues dicen esos son los machulas, eso es ch'ullpa [...]. (Fragmento de versión en quechua de Cesario Condemaita Monroe, 72 años, Lipuata, Marcapata, 12/7/2005)

La identificación de los ch'ullpa con el Inca Pacha Kuraka (« Señor Inca de la Tierra ») y los machula ( noción de ancestralidad que es incluso acentuada mediante el empleo del término $a w k i$, el cual entre otras cosas evoca también las nociones de descendencia por la línea paterna y, más precisamente, las de paternidad y autoridad ${ }^{55}$. Desde esta perspectiva, las fronteras que separan a los hombres de los ch'ullpa adquieren contornos de una imprecisión tal que dificulta la tarea de concebir a los segundos como seres totalmente extraños al destino de los humanos, presentes y pasados. ¿Qué ocurre al respecto con aquella otra porción de humanidad que pudo escapar hacia la selva cuando el sol despuntó por vez primera en el horizonte? Si bien salvajes e incivilizados, en su asociación con los ch'ullpa, los relatos marcapateños no avanzan más allá de atestiguar el carácter ambiguo de los ch'unchu. Pero hemos corroborado que en el ámbito más general del Ausangate, en el contexto del ritual de Quyllurit'i los ch'unchu también encarnan en parte la figura del inca (Ricard Lanata 2007). De igual forma, el mito de los indígenas de Pinchimuro cuenta que el señor de Quyllurit'i tenía en alta estima a las comparsas de ch'unchu de Paucartambo ya que se trata de los antepasados de los pobladores del distrito de Ccatcca y, en este sentido, los ch'unchu, descendientes de los machu que pudieron escapar por los ríos hacia la selva, son también concebidos como los ancestros de al menos una parte de la humanidad contemporánea (Gow 1974). En Ccatcca se encuentra el pueblo de Kauri, y allí sus habitantes, de acuerdo con la información relevada por Bernard Mishkin hace más de medio siglo, denominaban a los seres del tiempo pre-solar mediante el término auki. Sin pretender forzar la información etnográfica hacia conclusiones arriesgadas, lo cierto es que estas últimas consideraciones vuelven a ubicar sobre un mismo plano a ch'ullpa y ch'unchu, no ya como seres totalmente ajenos a la humanidad en tiempo y espacio ${ }^{56}$. 


\section{CONSIDERACIONES FINALES}

El mito de los ch'ullpa permite concebir los perfiles de una sociabilidad de contornos bastante precisos. En primer lugar, el mapeo de los sitios arqueológicos en los que se han identificado estructuras « ch'ullparias " parece coincidir con las zonas en las que el mito ha sido registrado. Es decir, existe una asociación entre la presencia de algún tipo de tumbas, monumentos funerarios o cuevas sepulcrales y los relatos sobre los seres del tiempo pre-solar. En segundo lugar, y en calidad de ch'ullpa propiamente dichos, los monumentos y sus moradores pertenecen, en principio, al área aymara, al eje acuático a lo largo del cual esta área se despliega y a las zonas aledañas o relativamente periféricas sobre las que eventualmente pudo haber ejercido algún tipo de influencia ${ }^{57}$. En tercer lugar, entre las poblaciones en las que se encuentra presente el mito, la actividad pastoril ocupa un rol significativo, estableciéndose nuevamente la asociación entre pastores, movilidad espacial sobre un eje definido - al menos desde el centro-sur de Bolivia hasta la antesala de la ceja de selva coincidente con el departamento peruano de Madre de Dios - y ch'ullpa, en cualquiera de sus dos versiones. Finalmente, todas estas poblaciones, sin excepción, están, o estuvieron hasta tiempos recientes, organizadas en ayllus. En Marcapata se encuentran conjugados todos estos elementos.

La ubicación geográfica del distrito de Marcapata - así como algunos aspectos de su morfología social - invita a ponderar el espacio en el que sus miembros organizan y desarrollan sus actividades como una suerte de límite. En primer lugar, se trataría de un límite espacial y ecológico sobre el que pasa la línea divisoria entre las tierras altas y las tierras bajas en esta porción de los Andes sur-peruanos; entre las poblaciones pastoriles dedicadas a la crianza de camélidos al pie de las faldas del Ausangate y aquellas otras comprometidas en el trabajo agrícola y, asimismo, entre estas poblaciones agrícola-pastoriles y aquellas del piedemonte amazónico. En segundo lugar, se trataría de un límite geográfico y político surcado por los trazos que separan los valles interandinos quechua y el altiplano aymara o, en otros términos, los territorios inabarcables del Collasuyu y los no menos inhóspitos del Antisuyu. En tercer lugar, se trataría de un límite social que demarca el universo quechua, rico y civilizado, del universo de la ceja de selva, pobre e incivilizado - remitiendo, en una misma asociación, a aquella otra demarcación entre los aymara y los uro-chipaya de las regiones lacustres del altiplano. Finalmente, se trataría también de un límite temporal en el sentido de que, tanto en la memoria como en el paisaje, todavía permanece el registro de una prehumanidad difícil de asir, que contrasta con la condición humana actual. Sin embargo, las diversas versiones del mito de los ch'ullpa registradas en Marcapata - en consonancia con otras provenientes del Ausangate - más que acentuar la condición limítrofe de cada una de las variables 
(ecológicas, políticas, sociales y temporales) mencionadas, parecieran más bien relativizarlas mediante un ejercicio intelectual que consistiría en conciliar y unir aquello que, en principio, aparece como antagónico y separado. Es decir, más que la diferenciación entre opuestos, los relatos en cuestión enfatizan su confluencia en un mismo espacio o universo social y, en este sentido, no sólo la misma noción de límite queda relativizada, sino también aquellos atributos que caracterizan aquella primerísima condición humana corporizada en la figura de los ch'ullpa. El ayllu marcapateño, íntimamente vinculado a las relaciones y las prácticas de parentesco de los hombres y mujeres que lo conforman, reconoce en los ch'ullpa a un ancestro, ser temido y reverenciado, con el cual resulta ineludible convivir.

Los cronistas de los siglos XVI y XVII no sólo registraron relatos similares en forma y contenido a los de los etnógrafos modernos sino que, además, el modo en que los legaron a las generaciones venideras remite a una contemporaneidad que no es sino la del propio mito. Así, por ejemplo, Guaman Poma de Ayala se refería a las prácticas mortuorias del Collasuyu de la siguiente manera:

[...] Y con ello entierran al defunto en los cinco días, como dicho es. En los dies días tornan a llorar y enbían otro tanto. Entonses los queman y dizen que, cuando la llama del fuego da sonido, dizen que lo rreciben los defuntos y que uan derecho a [...] Puqina Pampa y a Coro Puna, que allí se ajuntan. Y dizen que allí tienen mucha fiesta y conuersación entre los defuntos y defuntas. Que pasado dallí uan a otra parte adonde pasan muy mucho trauajo, hambre, sed y frío, en lo callente, mucho calor. Y aci le entierran con sus comidas y ueuidas y cienpre tienen cuydado de enbialles de comer y de ueuer. Y los seys meses hazen otro tanto sus fiestas de los defuntos y en el año, otro tanto. Pero no la sacan afuera al defunto como Chinchay Suyo a la procición al dicho defunto, cino que le dexan estar metido en su bóbeda, pucullo y le llaman amayam marcapa [« del muerto su pueblo »] [...]. (Guaman Poma de Ayala 1987, p. 290)

A mediados del siglo xvi, Cieza de León, en su crónica sobre el señorío de los incas, dedicó un capítulo a una de las tantas expediciones de Ynga Yupangue en el que se lee:

[...] Pasado esto, quentan más que reposó pocos días en el Cuzco porque quiso yr en persona a los Andes, adonde avía enbiado sus adalides y escuchas para que mirasen la tierra y le avisasen del arte que estavan los moradores della [...] Fue hecho así; y con los capitanes y jente de guerra salió del Cuzco [...] atraveçando las montañas y sierras nevadas supo de sus corredores lo de alelante y de la grande espeçura de las montañas [...] Como los naturales de aquellas comarcas supieron la entrada en su tierra del Ynga, como ya muchos dellos por manos de sus capitanes avían sido puestos en su señorío; le vinieron a hazer la mocha trayéndoles presentes de muchas plumas y aves y coca y de lo más que tenían en su tierra y a todos lo agradeçía mucho. Los demás yndios que avitavan en aquellas montañas, los que quisieron serle vaçallos, enbiáronle mensajeros, los que no, desanpararon sus pueblos y metiéronse con sus mugeres en la espeçura de la montaña. Ynga Yupangue tuvo gran notiçia que pasadas algunas jornadas, a la parte del Levante avía gran tierra y muy poblada. Con esta nueva, codiçioso de descubrirla, 
pasó adelante; mas siendo avisado cómo en el Cuzco avía çusedido çierto alvoroto, aviendo ya allegado a un pueblo que llaman Marcapata, rebolvió con prieça grande al Cuzco, donde estuvo algunos días. (Cieza de León, 1996, pp. 153-154)

Las costumbres mortuorias de los confines del Collasuyu tal y como las describe Guaman Poma de Ayala expresan un estrecho vínculo entre los vivos y los muertos: los primeros estaban obligados a ofrendar a los segundos quienes, a diferencia de lo que ocurría en otras regiones del Tawantinsuyu, nunca abandonaban el mundo que les había tocado en suerte, el Amayan Marcapa, en el que sufrían grandes pesares en «lo caliente, mucho calor». Por su parte, aquellos indios ch'unchu que no quisieron establecer un vínculo de vasallaje con el Ynga Yupangue en su incursión a los territorios inhóspitos del Antisuyu, se dirigieron hacia la espesura de las montañas, muy posiblemente siguiendo el curso de los ríos que siguieron aquellos ch'ullpa que pudieron escapar al cataclismo que produjo la salida del sol en la tierra. En cualquier caso, lo cierto es que Cieza de León es explícito al momento de describir la fascinación que los territorios ubicados en dirección al Levante ejercieron sobre el Ynga quien - y como siempre ocurre en este tipo de relatos - por alguna circunstancia excepcional fue impedido de avanzar en ellos llegando sólo hasta un pueblo llamado Marcapata. *

* Manuscrit reçu en juillet 2008, accepté pour publication en décembre 2009.

\section{NOTAS}

1. Las versiones del mito de los ch'ullpa consignadas en este artículo han sido recopiladas en 2005 durante un trabajo de campo en el ayllu Collana del distrito de Marcapata en calidad de investigador asociado al Centro Bartolomé de las Casas (Cusco, Perú). El balance bibliográfico que antecede la discusión del material marcapateño es producto de una estancia de investigación en la Universidad de St Andrews (Escocia) en 2006 patrocinada por el programa British Academy Visiting Fellowship 2006-2007 (VF2006/42688). Agradecemos a Xavier Ricard Lanata y Tristan Platt por su apoyo en las respectivas etapas de la investigación, a Georgina Maldonado por su ayuda en la trascripción y traducción de los relatos quechua y a María José Gassó, Diego Villar y los dos lectores asignados por el Journal de la Société des Américanistes por sus comentarios a una primera versión del manuscrito.

2. El sustantivo ch'ullpa (chullpa en aymara), al igual que el resto de los sustantivos en lengua vernácula, es consignado en este trabajo siguiendo la fonología quechua. Se ha omitido el empleo de la " -s » en el caso del plural, ya que ello reproduciría un uso castellanizado que no coincide con la marca quechua del plural (-kuma).

3. Una trascripción literal del relato fue publicada por Métraux (1935, pp. 396-397). Existen al menos dos referencias más tempranas del mito. Los indigenas de la provincia de Huancané (departamento de Puno, Perú) le contaron a Francisco Mostajo que las tumbas funerarias de la región fueron construidas por los primeros hombres para esconderse de la aparición del sol. Sin embargo, el autor desconocía si los indígenas empleaban la palabra ch'ullpa para designar a unos y otras (Mostajo 1923, p. 411). En una hacienda de Pelechuco (La Paz) un indigena de la provincia de Azángaro (Puno) le relató a Adolph Bandelier la historia de Juan Rubio, un individuo que durante el tiempo de los ch'ullpa apareció desde el este vaticinando la inminente salida del sol. Nada se supo de su destino más allá de la continuación de su viaje hacia el poniente. El mismo relato le fue repetido en Sicasica (provincia de 
Aroma, La Paz) (Bandelier 1904b, pp. 604-605). Bandelier (ibid.) relacionó el mito en cuestión con otros registrados por los cronistas de los siglos XVI y XVII relativos a personajes como el Tunupa de Carabuco (provincia de Camacho, La Paz) o el Contiti Viracocha del lago Titicaca.

4. En los Andes Centrales en general, y en el sur peruano en particular, el término « ayllu » remite a un principio de organización social propio de las poblaciones campesino-indigenas. El ayllu consiste en una agrupación de individuos unidos entre sí a través de vínculos de parentesco (de consanguinidad y alianza), que son los que definen la pertenencia al ayllu y los que imprimen su sello a las diversas actividades en las que sus miembros están comprometidos. El ayllu puede adquirir, y de hecho lo hace, formas diversas - duales, tripartitas, cuatripartitas, etc. (Sendón 2009).

5. El término apu alude a las divinidades tutelares corporizadas en la figura de montañas, cerros y cualquier accidente significativo del terreno. Para un tratamiento pormenorizado del particular en la región del Ausangate, ver Ricard Lanata (2007).

6. El ayllu Collana cuenta con poco más de 200 familias nucleares y está dividido en tres sectores cuyos nombres son Ch'umpi, Lacco y Accosiri. La encuesta etnográfica se ha concentrado hasta el presente en los dos primeros.

7. En este trabajo los términos « quechua » $y$ « aymara » se refieren a las áreas geográficas en las que las diversas versiones del mito discutido han sido registradas: a grandes rasgos, los Andes del centro y sur peruano y el altiplano del noroeste y centro de Bolivia, respectivamente. No se pretende con ello negar la variabilidad regional, étnica y social en el interior de cada una de las áreas, ni tampoco presentarlas como entidades inconmensurables.

8. El empleo del artículo femenino plural ("las») antes del sustantivo ch'ullpa obedece a la intención de distinguir « la ch'ullpa » como tumba funeraria de "el ch'ullpa» como ser del tiempo pre-solar.

9. No nos ocuparemos aquí de los escritos de los cronistas que se han pronunciado sobre las tumbas y costumbres funerarias en el Tawantinsuyu ya que ellos han sido objeto de tratamiento en las obras comentadas.

10. Cuatro décadas más tarde Jacques Sever (1921) publicó una breve descripción de las ch'ullpa de Corocoro como resultado de sus propias observaciones en la región.

11. Squier (1877) menciona a Johann Jakob von Tschudi como la fuente de este último registro, En efecto, en sus relatos de viaje, Tschudi (2003, pp. 248, 430-431) dedica unos breves pasajes a las pirámides de piedra que, sin denominarlas ch'ullpa, observó en la ruta entre Ayacucho y Huancavelica. El abra de La Raya, en el extremo sur del departamento del Cusco, marca el límite departamental con Puno y como hito geográfico constituye la puerta de entrada al Collasuyu. Precisamente en Lampa (actual provincia de Puno), Marcoy (2001, pp. 135-136) pudo observar una edificación a la que su guía denominó « obra de los gentiles aimaras ». El viajero caracterizó el edificio como una ch'ullpa y anotó, en su diario, que ella era obra de los antepasados de la humanidad (aymara) actual. Estos antepasados vivieron en la oscuridad tras sucesivas desapariciones (cuatro) del sol sobre la faz de la tierra. Las ch'ullpa de Sillustani, en el lago Umayo, y otras en las alturas de Vilque recibieron también la atención de Wiener (1993, pp. 570-572).

12. En quechua machay significa " cueva » y samay « descansar » $\mathrm{y}$ « respirar ».

13. Sobre Tunupa, el autor cita un cronista que menciona que el viaje de este personaje cubre un periplo que comienza desde algún sitio de Brasil y alcanza el extremo sur de Bolivia (Bandelier 1904b, p. 612).

14. El término quechua ch'unchu (ch'unch'u en aymara) significa « hombre oriundo de la selva " y " salvaje ». Uno de los sentidos de guarayo, a su vez, es el de " enemigo » (Nordenskiöld 1906, p. 122).

15. Si bien las hipótesis de Posnansky sobre la materia han sido cuestionadas por la literatura posterior, uno de los escritos citados contiene una serie de observaciones que son dignas de destacar en virtud de la discusión que sigue. En primer lugar, la asociación de las ch'ullpa-o "chullpares ", o "gentilares »-con casas o pueblos abandonados está fundamentada en el hecho de relativizar la separación de las viviendas y los sitios destinados a lo muertos, en el sentido de que ambos podían coexistir en una sociedad cuyo culto principal era aquel destinado a los antepasados, mallki o achachila 
(Posnansky 1912, pp. 80-81). Una opinión similar fue sostenida en relación con los restos del sitio de Maukallajta (cercano al distrito alpaquero de Ñuñoa, provincia de Melgar, Puno), en el que convergían una serie de caminos que vinculaban las regiones mineras de Carabaya y las quebradas de Canchis (Franco Inojosa y González 1936, p. 166). En segundo lugar, algunos de los monumentos descritos son asociados a los que estaban en uso entre los indigenas de la «comunidad 》 Collana que, sin mayor especificación, estaba localizada al sur de La Paz (Posnansky 1912, p. 82). El estado de los restos óseos conservados en algunas ch'ullpa parecían sugerir que individuos enterrados en vida se hubieran comido entre sí (ibid., p. 38), al igual que lo hicieron los ch'ullpa ante la inminente salida del sol (ibid., p. 84).

16. Es por lo demás sugestivo que uno de los topónimos del sitio en cuestión remita al término aymara tumu - raíz de Tunupa - el cual encierra el sentido general de « antepasado » o « ancestro » (Bertonio 1984, p. 364; Platt et al. 2006, pp. 663-664). En el pueblo wanka de la misma provincia, Gutiérrez Noriega $(1937$, p. 48 ) volvió a documentar ch'ullpa asociándolas nuevamente con poblaciones pastoriles y ayllu ganaderos.

17. Los términos amaya y amaya uta significan, en aymara, "cuerpo muerto » y " sepultura » (Bertonio 1984, p. 15). Lari, por su parte, designa al «tío, hermano de la madre », a los " parientes varones de parte de la madre clasificados bajo el mismo término » y, en su duplicación, a los « habitantes de la puna que no reconocen autoridad política » (ibid., p. 191). Para una discusión sobre este último término ver, por ejemplo, los trabajos de Bouysse-Cassagne (1986, pp. 213-215), Platt et al. (2006, p. 664) y Zuidema (1990, pp. 25-26).

18. Para esa época se había reportado la presencia de ch'ullpa en los sitios de Chaquí y Lipez al sur de Bolivia (Ibarra Grasso 1953) y estructuras similares, sin recibir la misma denominación, en la Quebrada de la Vaca al sur de la costa peruana (Rowe 1956). También de esa época proceden pronunciamientos sobre la materia a partir del debate acerca del problema de la unidad cultural de la región del Titicaca (Tschopik 1946; Bennett 1950).

19. En las provincias de Oruro, Poopó y Carangas del departamento de Oruro, Alcide d'Orbigny identificó e inspeccionó un importante número de ch'ullpa, y cada una de sus descripciones es acompañada por una referencia a las poblaciones pastoriles que residían cerca de los sitios observados. La impresión que generaron en él las tumbas funerarias parece haber sido la misma que la impresión que le provocaron los rebaños de alpacas y llamas de la altiplanicie (d'Orbigny 2002, pp. 1650, 1664, 1667-1668, 1671-1673).

20. «Chullpa; Entierro o seron donde metian sus defuntos » (Bertonio 1984, p. 92).

21. El análisis de los ejemplares localizados en los territorios del antiguo señorío pakasa en Bolivia vuelve a relacionar las ch'ullpa con lugares de culto en memoria de autoridades, linajes o ayllus (Kessely y Pärssinen 2005, p. 382). Por otra parte, la tradición «chullparia » no estaría circunscrita a los territorios altos de los Andes ya que, según los autores, se han encontrado torres funerarias en el piedemonte de la Cordillera Real y en el área selvática del Beni (ibid., p. 383).

22. En su Diccionario quechua Cuzco Collao, Antonio Cusihuaman define awki de la siguiente manera: « Ser sobrenatural relacionado con los antepasados, y que habita invisiblemente sobre la tierra en lugares aislados de las poblaciones. Espíritu que intermedia entre el muerto y la persona viva [...] 》 (Cusihuaman 2001, pp. 26-27).

23. Soq'a es una « especie de tumor en el cuerpo atribuido a fuerzas sobrenaturales » (Cusihuaman 2001, p. 103); pukyu o puhu significa « manantial » o " fuente de agua ». En un estudio sobre medicina aymara, Weston La Barre (1951, p. 177) consigna el empleo de minerales pulverizados y hervidos para contrarrestar el mal causado por el ch'ullpa. Los pastores de la región del Ausangate consideran a los lagos y manantiales que inundan la región como puertas de entrada al inframundo, lugar de residencia del rayo que, asociado con la figura de los apu, conserva el animu - o « fuerza eficaz que anima a todas las cosas y las conduce a su plena realización » (Ricard Lanata 2007, p. 78) - de los seres que fulminó tras su paso por la tierra. Junto con las grutas y cuevas que conservan los huesos de los machula o " ancestros del tiempo pre-solar », estos sitios son decididamente peligrosos, particularmente durante las horas phiru en las que el cielo adquiere el tono de una bóveda metálica confundiendo a los seres y sus sombras (Ricard Lanata 2007, pp. 167-191). En la provincia de Huanta (Ayacucho) los seres del tiempo 
pre-solar son conocidos bajo el nombre de « gentiles » o ñaupa runacuna (ñawpa runakuna u « hombres antiguos »), cuyos restos se conservan en cuevas. Cuando algún desprevenido se tiende a descansar cerca de ellas cae presa de una enfermedad que sólo puede ser curada haciendo calentar los cacharros de los mismos gentiles (Trejo 1944, p. 93). Entre algunos aymara, la introducción de un fragmento de hueso humano en el cuerpo es concebida como enfermedad de los ch'ullpa (Tschopik 1946, p. 569).

24. En otro sitio Mishkin vuelve a comentar el mismo mito observando que los únicos espíritus maléficos en Kauri son los de aquellos niños que encuentran la muerte antes de ser bautizados. Sus restos son enterrados en las alturas de las montañas y las cenizas de los infantes masculinos sirven para combatir el soq'a wayra o "enfermedad de los vientos » (Mishkin 1946, p. 464).

25. La versión de la provincia de Huanta (nota 23) precisa un aspecto más de la condición de los gentiles: en las noches de eclipse se escuchan las voces gangosas de los huesos conservados en las cuevas profiriendo conjuros conocidos bajo el nombre de iñini (del verbo quechua iniy, " creer ", " tener fe ») pero sin pronunciar correctamente la letra ñ, ya que de hacerlo el mundo caería presa de un terrible cataclismo (Trejo 1944, p. 93).

26. El comercio sexual entre un hombre y la soq'a paya produce una enfermedad (payasqa) que sólo puede curarse ubicando, mediante sueños o la consulta de un chamán, la osamenta de la paya con el fin de desenterrarla y quemar sus huesos para ingerir, hervidas, sus cenizas. Los vientos que entran en contacto con las tumbas y manantiales asociados al tiempo de los ñawpa son causantes de enfermedades (soq'a wayra y pukyo wayra) que los hombres sólo pueden prevenir amarrando en sus tobillos o muñecas trozos de lanas torcidos hacia la izquierda (lloq'e o lloq'esqa) (Núñez del Prado Béjar 1970, pp. 86-89). Para una descripción del departamento de Cusco sobre las consecuencias del intercambio sexual con el soq'a machu, ver Flores Ochoa (1973).

27. Recientemente se ha observado que los q'ero reconocen en los cementerios antiguos de sus territorios las tumbas de sus antepasados ñawpa y, aunque les admiten un rol civilizador, rechazan cualquier filiación con los incas - asociados con la figura de Inkarri (Le Borgne 2005, p. 165).

28. En este sentido, los ñawpa conmemoran la figura misma de los apu quienes, en calidad de pastores sobrenaturales, también tienen a los zorros por perros, a los cérvidos por mulas, a las vicuñas por llamas o alpacas, a los cóndores por gallinas y a los zorrinos por cerdos (Ricard Lanata 2007, p. 64). Esta inversión no se restringe al universo de los apu ya que, en calidad de animal salvaje (salqa), el zorro es también el perro de los gentiles, ancestros del tiempo pre-solar (La'Riva González 2005, p. 22).

29. En un escrito posterior (nota 3 supra) dedicado a la provincia de Huancané (Puno), Mostajo (1952, p. 182) se refirió al sol de los ayanques (aya, « cadáver ») como « sol de los gentiles », por su tono amarillento y triste. Por su parte, Ibarra Grasso consignó una breve referencia de un indigena de Chuquisaca (Bolivia), quien le contó que para los gentiles «el sol sale del mismo lado que para nosotros, porque están dados vuelta » (Ibarra Grasso 1961, p. 186).

30. Las versiones q'ero del mito, recopiladas in situ en 1955, difieren de las registradas unos años antes en Puquio (provincia de Lucanas, Ayacucho) en que estas últimas se circunscriben a las hazañas de Inkarri, sin mencionar nada acerca del mundo y los seres que habitaban en él antes de su aparición (Arguedas 1975). Por otro lado, el término kuyo (kuyuq y kuyuy, en quechua, significan « movible » y " moverse »), da cuenta del carácter migrante de la población de Hatun Kuyo: según los indígenas, ellos descienden de un pastor que habitaba en las proximidades de un cerro ubicado en el camino hacia Lares en la provincia de Calca, que limita al este con la provincia de Paucartambo y al sur con la de Quispicanchi (Casaverde Rojas 1970, p. 124).

31. En su nosologia aymara, La Barre (1951, p. 174) menciona que un remedio contra el paludismo es la ingestión de la carne del añatuya o zorrino (añas en quechua), quien suele vagabundear por las noches destrozando los campos de cultivo rodeado de un brillo fosforescente y resplandeciente como fuego.

32. Según Duviols (1973, pp. 161-162), la confusión en torno del origen mítico y geográfico de los huari no debe interpretarse en términos antagónicos. Si bien la humanidad solar fue concebida en las riberas del lago Titicaca, la historia del primer antepasado huari puede relacionarse con la de un personaje que tras la creación, y cual Tunupa o Viracocha, emprende un viaje subterráneo hacia el 
Oeste y resurge de una pacarina («lugar de origen», del verbo quechua paqariy, «nacer» o " amanecer ») sometiéndose a un nuevo ciclo de aventuras y desventuras.

33. Zuidema ofrece otra interpretación de las fuentes empleadas por Duviols que vuelve a invertir los atributos asociados a los términos opuestos. Los dos grupos, los conquistadores foráneos y los conquistados locales, eran denominados llachua y llacta. Mientras los primeros ofrecían culto al rayo, los segundos adoraban al dios subterráneo Huari. Además, cada grupo tenía una ancestra que, surgida de un lago, había creado las llamas y las plantas comestibles. El origen común de la clase inferior y las llamas estaria relacionado con el sentido de los términos llachua y llacta. El segundo está asociado con la noción de "villa » o " pueblo » y el primero con la práctica del llachuar o el «sacrificio de las llamas ». En este sentido, la segunda de las clases estaria identificada con las llamas, mientras que la clase de los conquistadores con sus sacrificadores (Zuidema 1973, p. 17). Para un análisis en el que los huari son nuevamente identificados con los machu o gentiles y, en calidad de tales, con « humanos en estado de naturaleza " o " antepasados prehumanos » que residen en los límites entre ecologías contrastadas, ver Molinié Fioravanti (1986-1987, pp. 252-269).

34. En quechua, ñuñu significa " seno » $\mathrm{o}$ " teta " y hap'iy es el infinitivo de los verbos « encender » y « coger » o « agarrar ». La traducción de hapiñuñu, entonces, además de « seres con tetas largas de las cuales podian agarrarse " (Bouysse-Cassagne y Harris 1987, p. 24) podria ser también "seres con senos encendidos », lo que de algún modo evocaría su carácter nocturno, vinculado con el zorrino fosforescente lari.

35. Para una asociación explícita entre los términos mencionados y los ch'ullpa, ver BouysseCassagne y Harris (1987, pp. 37, 40, 43, 50). El mito también asocia la figura de Tunupa con los chuqila. Así como en el héroe aparecen conjugados elementos antagónicos como el agua y el fuego, el cluqqila cazador es aquel que transita el borde entre los universos de la sociabilidad y el salvajismo, desdibujando las fronteras entre lo cultivado y lo yermo, lo fértil y lo estéril y el sol y la noche (ibid., p. 27). Wari también refiere a un ser rubio con cuerpo de vicuña (ibid., p. 23). Por otra parte, con motivo de la cosecha de papas se celebraba en el Collao el ritual de sucullo, en el que los niños de pecho eran llevados al centro del pueblo y se les untaba la cara con sangre de vicuñas sacrificadas cuya carne, después, era repartida entre sus madres. Este acto, que marcaba el ingreso del niño al universo social, era prerrogativa del tío materno o lari (Bouysse-Cassagne 1986, pp. 213-214).

36. Otro relato sobre los ch'ullpa proveniente de una comunidad quechua al norte de La Paz los describe como una pareja de ancianos extremadamente pequeños (Bouysse-Cassagne y Harris 1987, p. 37).

37. Análisis recientes sobre el peregrinaje hacia Quyllurit'i vuelven a identificar la estrecha asociación entre los ch'unchu y la pre-humanidad que vivia sin sol en contraposición a las comparsas de qhapaq qulla (qhapaq, « rico » o " adinerado »), que simbolizan el tiempo de la humanidad presente y socializada. Entre ambas se insertan los bailarines ukuku quienes, en calidad de osos con anteojeras pertenecientes al piedemonte tropical, transitan el territorio intermedio que divide los de los respectivos, asi entendidos, contrarios (Molinié 2005, pp. 73-74). Precisamente, las dicotomías que oponen a los ch'unchu y qulla se establecen sobre cuatro planos: espacial (tierras bajas-tierras altas), temporal (era de los machula-era de Inkarri), cultural (salvaje-civilizado) y social (pobres-ricos). Sin embargo, debido a su atuendo los ch'unchu mismos son personajes mediadores. Mientras que sus lanzas de madera de chonta los vinculan con las tierras bajas, sus plumas de ara (asociadas a los apu y los reyes incas) remiten al universo de las tierras altas. Se trata de seres del piedemonte, espacio liminal entre los universos contrastados (Ricard Lanata 2007, pp. 263-264). La oposición entre los ch'unchu y los qulla vuelve a expresarse en ocasión de la celebración de la fiesta de la Virgen del Carmen en Paucartambo, pero sobre un plano relativamente distinto. Aquí los primeros vuelven a representar a los selváticos y los palúdicos (o chukchu, sátira de los agricultores que trabajan en la ceja de selva) y los segundos a los muleteros o llameros asociados al altiplano que transportan productos entre la sierra y la selva. Para los paucartambinos los qulla, si bien civilizadores, son también personajes foráneos, advenedizos y licenciosos con quienes el intercambio matrimonial está fuertemente censurado, salvo que los segundos se adecuen a la regla de residencia uxorilocal - lo que subraya, a su vez, que en términos ecológicos al 
antagonismo qulla-ch'unchu se le suma otro, relativo a la oposición qhiswa-qulla (qheswa o " quebrada o valle plano de clima templado o moderado surcado por un río principal " y qolla o " habitante oriundo del altiplano ") (Gaillard 2005; Ricard Lanata 2007, pp. 265-266, s. d.). Los indígenas de Hatun Kuyo cuentan un mito relativo al origen del paludismo en el que se lo asocia con una pareja incestuosa que fue expulsada hacia la selva en donde encontró la muerte en manos de los ch'unchu. Pasado el tiempo, un salvaje excavó el sitio en el que había sido enterrada permitiendo salir a sus huesos y expandir la enfermedad sobre la tierra (Casaverde Rojas 1970, p. 204).

38. En Sonqo, el tema de los antepasados está intimamente ligado al problema del origen y constitución del ayllu. Los ancestros originales de Sonqo fueron tres seres que brotaron de tres sitios sagrados. Ellos fueron reemplazados, cuando el sol los quemó, por los rumakuma, quienes igualmente tenían tres autoridades. Estos primeros hombres también fueron destruidos durante la era de la plaga (pisti timpu), tiempo en el cual los padres desenterraban las tumbas de sus hijos para comerlos y a los infantes les era permitido alimentarse del pecho de sus madres muertas. Se trata de un tiempo invertido en el que los animales comían a sus dueños humanos, los padres ocultaban los alimentos a sus niños y no podía encontrarse dinero en ningún sitio. Esta era, finalmente, fue sucedida por otra en la que tres líderes volvieron a fundar el ayllu Sonqo conservando su misma estructura (Allen 2002, pp. 76-80). El mito de creación de la iglesia de Marcapata se inscribe en otro mito relativo a la fundación del mismo pueblo, en la que estuvieron involucrados tres padres procedentes de Asia (Sendón 2009). Otra versión del mito adjudica a los mismos ch'ullpa la fundación de la iglesia (Ricard Lanata 2007, p. 451).

39. El elemento de mediación son los mismos chipaya, apreciados por sus poderes mágicos y entre quienes los aymara buscan padrinos para sus hijos por resultar auspiciosos (IVachtel 2001, p. 143).

40. Los k'ulta reconocen en un tipo de papa minúscula y algunas plantas el alimento de los ch'ullpa. En otra versión del mito los ch'ullpa, persiguiendo a Tatala, le preguntaron acerca de él a un hombre que estaba cosechando la tierra. Sin embargo, los k'ulta afirman que los ch'ullpa bien pudieron « conocer » acerca del fuego y de la cosecha, pero el « cuándo » y el « dónde » es prerrogativa de Tatala (Abercrombie 1998, pp. 325, 327).

41. Layra también significa " ojo ». Muchas torres funerarias (ch'ullpa) tienen sobre sus puertas dos pequeñas aberturas que hacen de ojos tanto para los adoradores que se acercan a ellas como para los seres que hay en su interior (Abercrombie 1998, pp. 181-182). Vale la pena recordar, en este contexto, la descripción de Bouysse-Cassagne acerca del rol destinado al lari en ocasión de la celebración del ritual sucullo (nota 35).

42. Según Arnold (1993), los campesinos del ayllu Qaqachaka (Oruro) reconocen descender de los ch'ullpa (citado en Abercrombie 1998, p. 495).

43. En la versión del mito que ofrece Baumann, el relator reconoce que sus antepasados no tenían nombres y que fueron los aymara quienes se los otorgaron, tras haberlos cazado (Baumann 1981, pp. 173-174).

44. Un elemento que destaca al grupo de danzantes es el adorno chiriguano, consistente en una especie de abanico atado en un palo largo (Baumann 1981, p. 178). Los wayri ch'unchu del ritual de Quyllurit'i son también designados pukapakuri, aludiendo de este modo a las plumas rojas que adornan sus trajes (Gow 1974, p. 71), Ilamadas también ara en alusión a un ave tropical (Molinié 2005, p. 73; Ricard Lanata 2007, p. 264, nota 37). Los danzantes ch'unchu de Kalankira usan una máscara a la que se agrega una peluca despeinada confeccionada con lana de llama (Stobart 2006, p. 188). En la provincia puneña de Huancané, en territorio peruano, también se realiza una vez al año una celebración conocida como danza de los chiriguanos (Valencia Chacón 1981).

45. En estricto rigor, Platt establece una analogía entre el parto humano y la transformación mito-histórica del surgimiento del sol y la aniquilación de los ch'ullpa en términos de la oposición " antepasados lunares » y "sol cristiano ». En este sentido, la culminación de la formación de la persona está relacionada con su conversión en « nuevo cristiano », el bautismo y el otorgamiento de un nombre (Platt 2001, pp. 635-636, 664).

46. Además de los casos referidos en la literatura que asocian « las » ch'ullpa con la organización en ayllus, es interesante constatar que uno de los ayllus de la provincia de Chayanta (Potosí) lleva 
literalmente el nombre de Chullpa, y que en los territorios de la antigua confederación Qaraqara Charka se encuentra también un sitio arqueológico denominado Chullpa Qasa (o "paso de las ch'ullpa »), denominado también " camino de las almas » (o alma ñan). Este último es considerado por los macha como la ruta que siguen los muertos en dirección al Pacífico, en donde se dice que cultivan aji en los valles del norte de Chile (Platt et al. 2006, pp. 56, 501, 504).

47. Por razones de espacio no es posible incluir la trascripción de los relatos en quechua, a los que dedicaremos un trabajo particular.

48. Los pobladores de Kalankira denominan a la cara de una gran roca al pie de un sendero cercano a una apacheta yawlu iglesia (" iglesia del demonio ») y la adjudican a la época de los ch'ullpa (Stobart 2006, p. 60).

49. Hemos visto que el mismo carácter es asignado por los campesinos de Sonqo a sus ch'ullpa.

50. Lo que recuerda, a su vez, que un preventivo para la enfermedad de los ch'ullpa entre los indigenas de Qotabamba consiste en amarrarse a los tobillos y muñecas un trozo de lana torcido, precisamente, hacia la izquierda (nota 26). El hilado en dirección izquierda remite a una imagen especular: si la luna era el sol de los ch'ullpa, es previsible que sus tejidos fueran simétricamente inversos a los que confeccionan los humanos.

51. Los pobladores de Hatun Kuyo consideran que el beso o el acto de besar es una costumbre occidental, cuyo equivalente local es el sunkha, o " pasar la barbilla por la frente », acto frente al cual los indígenas no sólo se muestran reacios sino que incluso consideran una ofensa, ya que es a través del " beso » que el machu imprime sobre los niños indefensos su sello mortal (Casaverde Rojas 1970,p. 158).

52. En su discusión sobre el problema de las relaciones entre incas y anti, Renard Casevitz et al. (1988) mencionan una práctica en cierto modo asociada con la uxorilocalidad al momento de la celebración de una alianza entre ambos grupos: el inca o su hijo desposan en la selva a mujeres y allí dejan su descendencia en lugar de llevar a unas y otras a la capital imperial (ibid., p. 124). Ello recuerda, sobre un plano inverso, la misma dinámica entre paucartambinos y qulla, siendo en este caso los segundos quienes deben someterse a la regla en cuestión (nota 37). En relación con la presencia del Collao en el Cusco, es valioso recordar que los pastores de Chillihuani afirman que sus antepasados llegaron a sus tierras desde la región de Puno y el lago Titicaca, que los indigenas de Hatun Kuyo dicen descender de un pastor de la zona de Lares (nota 30) y que uno de los ayllus marcapateños lleva por nombre Collasuyu.

53. El alcalde al que el informante hace referencia es efectivamente un chamán reputado y suele actuar como tal en las porciones bajas del territorio distrital.

54. El mito de Sonqo cuenta que, cuando salió el sol, los machula se vieron privados de dinero, lo que sugiere que antes de su aparición disponían de él (nota 38). Los indigenas del ayllu Laymi del norte de Potosí reconocen diversos tipos de dinero, entre los cuales destaca el ch'ullpa qulli (o qolqe, " plata " o " dinero »), que se encuentra escondido bajo tierra. Se trata, en rigor, no de dinero sino de una fuente de acceso a él que, además, está asociado a las venas de los minerales escondidas en el corazón de las minas (Harris 2000b, pp. 52,73). Las tumbas de los laymi erigidas en honor de los muertos también son sitios de poder ambiguo, e incluso en regiones adyacentes los huesos conservados en ellas son empleados como medios de adivinación (Harris 2000a, p. 31). Lo mismo sucede con los huesos de los antiguos de los indigenas de las provincias de Calca y Chumbivilcas (Cusco) para quienes, una vez que se secan, detentan un carácter inofensivo (Robin 2005, p. 58).

55. Mientras que en Platt et al. (2006) se identifica al awki con el mayor o más apto de los tios paternos, sustituto en temas de sucesión del padre muerto o retirado por enfermedad (ibid. p. 664), en la entrada correspondiente del diccionario de Bertonio se lee: « Auqi: Padre, o Señor » (Bertonio 1984, p. 28, nota 22). La identificación de los ch'ullpa con ancestros de los cuales desciende la humanidad actual no es patrimonio exclusivo de los marcapateños. Hemos visto que los miembros del ayllu Qaqachaka en Oruro se conciben como descendientes de ellos (nota 42), así como también los pastores de Chillihuani y los runakuna de Sonqo.

56. Meses después de terminar de escribir estas páginas llegó a nuestras manos la versión del mito de origen de la comunidad de Usi (provincia de Quispicanchi), cuyos pobladores también relatan la 
historia del fin de los gentiles (suq'a machula o ch'ullpa) vinculándolos con las zonas de pastoreo de la puna alta. Cuenta el mito que en los tiempos pretéritos, los antiguos Usi y los antiguos Sangarará vivían en continuas reyertas. Los segundos invadieron los territorios de los primeros y estos últimos tuvieron que recurrir a la ayuda de un tal Antisuyu que se había establecido en su territorio en calidad de yerno (qatay) y que, con la ayuda de sus compañeros de la selva y de un viento favorable del Qollasuyu, logró expulsarlos con éxito y distribuir los territorios agrícolas tal y como se los aprecia actualmente. De yerno, forastero y guerrero no incorporado plenamente al grupo de su esposa, con la salida primigenia del sol Antisuyu deviene ayllu y, junto con su par Usi, tiene pleno derecho sobre el territorio del grupo (Itier 2007, pp. 27-45). Este mito no sólo vuelve a poner en relación los términos ayllu, ch'ullpa, Collasuyu, Antisuyu y « zonas de pastoreo » en una región que no es sino la misma en la que se encuentra Marcapata (Quispicanchi) sino que también, y quizás fundamentalmente, constituye una instancia excepcional en la que el ch'unchu, asociado con el héroe Antisuyu, puede ser concebido como un ancestro.

57. La ausencia de registro, al menos hasta donde conocemos, del mito en el norte peruano constituiría otro motivo para desconfiar acerca de una asociación directa entre las sepulturas abiertas descriptas por Isbell para gran parte de los Andes Centrales y la tradición del altiplano sur (nota 21). Sin embargo, en una conferencia dictada en la ciudad de Buenos Aires en octubre de 2007 sobre tecnología hidráulica y pastoralismo en el departamento peruano de Ancash, el arqueólogo británico Kevin Lane no sólo identificó la presencia de ch'ullpa en las estancias de pastoreo de las zonas altas de la Cordillera Negra (Callejón de Huaylas), sino que también manifestó haber escuchado el mito entre los pobladores de la región. Una versión reciente del mito, esta vez asociado a la figura de los gentiles, procede del pueblo de Llampa (provincia peruana de Jauja, departamento de Junín), y el autor que lo ha registrado le adjudica un carácter " panandino " (Rivera Andía 2006, pp. 141-144). Si bien es cierto que ch'ullpa, gentiles, ñawpa etc., son homologables en la gran mayoría de los relatos, una serie de características del mito en relación con otros aspectos de la dinámica social de las poblaciones campesino-indígenas del Ausangate y el sur peruano permiten trazar lineas comparativas bastante significativas hacia el Collasuyu. En todo caso, en su introducción a una serie de versiones q'ero registradas a fines de la década de 1970, Juan Ossio reconoció que, si bien se presentan una serie de " elementos panandinos ", la " tradición cultural " del departamento del Cusco contrasta marcadamente con otras "tradiciones culturales ", como los casos de los departamentos de Ayacucho y Anchash (Müller y Müller 1984, p. 126).

\section{REFERENCIAS CITADAS}

ABERCROMBIE Thomas A.

1998 Pathways of memory and power: Ethnography and history among an Andean people, The University of Wisconsin Press, Wisconsin.

\section{Allen Catherine J.}

1982 "Body and soul in Quechua thought ", Journal of Latin American Lore, 8 (2), pp. 179-196.

1984 "Patterned time: the mythic history of a Peruvian community », Journal of Latin American Lore, 10 (2), pp. 151-173.

2002 The hold life has. Coca and cultural identity in an Andean community, Smithsonian Institution Press, Washington/London [1988].

\section{Arguedas José María}

1975 "Puquio, una cultura en proceso de cambio. La religión local », in José María Arguedas, Formación de una cultura nacional indoamericana, México, Siglo xxi editores, pp. 34-79 [1956]. 
ARNOLD Denise

1993 "Adam and Eve and the red-trousered ant: history in the Southern Andes ", Travesia, 2 (1), pp. 49-83.

BANDELIER Adolph F.

1904a "On the relative antiquity of ancient Peruvian burials ", Bulletin of the American Museum of Natural History, XX, pp. 217-226.

1904b "The cross of Carabuco in Bolivia ", American Anthropologist, 6 (5), pp. 599-628.

1905 "The basin of Lake Titicaca ", Bulletin of the American Geographical Society, 37 (8), pp. 449-460.

\section{Baumann Max P.}

1981 "Music, dance, and song of the Chipayas (Bolivia) », Latin American Music Review, 2 (2), pp. 171-222.

BenNetr Wendell C.

1950 "Cultural unity and disunity in the Titicaca basin ", American Antiquity, 16 (2), pp. 89-98.

BERTONIO Ludovico

1984 Vocabulario de la lengua Aymara, Centro de Estudios de la Realidad Económica y Social/Instituto Francés de Estudios Andinos/Museo Nacional de Etnografia y Folklore, Cochabamba [1612].

BoLIN Inge

1998 Rituals of respect. The secret of survival in the High Peruvian Andes, University of Texas Press, Austin.

Bossert Federico y Diego VillaA

2007 "La etnología chiriguano de Alfred Métraux », Journal de la Société des Américanistes, 93 (1), pp. 127-166.

BouYSSE-CASSAgne Thérèse

1986 "Urco and uma: Aymara concepts of space", in John V. Murra, Nathan Wachtel y Jacques Revel (eds), Anthropological history of Andean polities, Maison des sciences de l'homme/Cambridge University Press, París/London, pp. 201-227 [1978].

BOUYSSE-CASSAGNe Thérèse y Olivia Harris

1987 "Pacha: En torno al pensamiento aymara », in Thérèse Bouysse-Cassagne, Olivia Harris, Tristan Platt y Verónica Cereceda, Tres reflexiones sobre el pensamiento andino, Hisbol, La Paz, pp. 11-59.

Casaverde Rojas Juvenal

1970 «El mundo sobrenatural en una comunidad», Allpanchis Phuturinqa, II, pp. 121-243.

Cieza de León Pedro de

1996 Crónica del Perú. Segunda parte, Pontificia Universidad Católica del Perú, Lima. 


\section{Cusinuaman Antonio}

2001 Diccionario quechua Cuzco Collao, Centro Bartolomé de las Casas, Cuzco.

Champi CCASA Florentino

1996 "Inka iglesia waskichakkuy (techado del templo inka)», Andinidad, 1, pp. 201-212.

Dillon Mary F. y Thomas A. Abercrombie

1988 "The destroying Christ: an Amayara myth of conquest », in Jonathan D. Hill (ed.), Rethinking history and myth. Indigenous South American perspectives on the past, University of Illinois Press, Urbana, pp. 50-77.

D'OrBigny Alcide

2002 Viaje a la América Meridional, Tomo IV, Instituto Francés de Estudios Andinos/Plural Editores, La Paz [1835].

Duviols Pierre

1973 «Huari y Llacuaz. Agricultores y pastores. Un dualismo prehispánico de oposición y complementaridad », Revista del Museo Nacional, XXXIX, pp. 153-191.

FORBES David

1870 "On the Aymara Indians of Bolivia and Peru », The Journal of the Ethnological Society of London, 2 (3), pp. 193-305.

Flores OCHOA Jorge A.

1973 «La viuda y el hijo de Soq'a Machu. El caso de un infanticidio tolerado, aceptado y exigido ", Allpanchis, V, pp. 45-55.

Franco Inojosa José M.

1937 «Informe sobre reconocimiento de restos arqueológicos en las cabeceras del Paucartambo ", Revista del Museo Nacional, VI (2), pp. 255-277.

Franco Inojosa José M. y Alejandro González

1936 « Exploraciones arqueológicas en el Perú. Departamento de Puno », Revista del Museo Nacional, V (2), pp. 157-183.

\section{Gaillard Patricia}

2005 «La danza de los chukchu. Danza, enfermedad y devoción en los Andes peruanos del sur (departamento del Cuzco) ", in Antoinette Molinié (ed.), Etnografias de Cuzco, Laboratoire d'ethnologie et de sociologie comparative/ Centro Bartolomé de las Casas/Instituto Francés de Estudios Andinos, Nanterre/Cuzco, pp. 89-110.

Glave Luis Miguel

1989 Trajinantes. Caminos indigenas en la sociedad colonial siglos XVI-XVII, Instituto de Apoyo Agrario, Lima.

Gow David

1974 "Taytacha Qoyllur Rit'i. Rocas y bailarines, creencias y continuidad ", Allpanchis, VII, pp. 49-100. 
Gow David y Rosalind Gow

1975 "La alpaca en el mito y el ritual », Allpanchis, VIII, pp. 141-162.

Guaman Poma De Ayala Felipe

1987 Nueva crónica y buen gobierno, tomo A, Historia 16, Madrid [1615].

GutiérRez Noriega Carlos

1935 "Jatun Malka », Revista del Museo Nacional, IV (1), pp. 105-110.

1937 "Ciudadelas chullparias de los Wankas », Revista del Museo Nacional, VI (1), pp. 43-51.

Harris Olivia

2000a "The dead and the devils », in Olivia Harris, To make the earth bear fruit. Ethnographic essays on fertility, work and gender in Highland Bolvia, Institute of Latin American Studies/University of London, London, pp. 27-50 [1982].

2000b "The sources and meanings of money: beyond the market paradigm ", in Olivia Harris, To make the earth bear fruit. Ethnographic essays on fertility, work and gender in highland Bolvia, Institute of Latin American Studies/University of London, London, pp. 51-74 [1985].

HYSLOP John

1977 "Chulpas of the Lupaca zone of the Peruvian high plateau », Journal of Field Archaeology, 4 (2), pp. 149-170.

IBARRA Grasso Dick E.

1953 "New archaeological cultures from the departments of Chuquisaca, Potosí and Tarija, Bolivia », American Antiquity, 19 (2), pp. 126-129.

1961 «La verdadera historia de los Incas (deformaciones ideológicas en la historia oficial del antiguo Perú) ", Revista Mexicana de Sociología, 23 (1), pp. 169-202.

ISBELL William $\mathrm{H}$.

1997 Mummies and mortuary monuments. A postprocessual prehistory of Central Andean social organization, University of Texas Press, Austin.

ITIER César

2007 El hijo del oso. La literatura oral quechua de la región del Cuzco, Instituto Francés de Estudios Andinos/Instituto de Estudios Peruanos/ Fondo Editorial de la Pontificia Universidad Católica del Perú/Fondo Editorial de la Universidad Nacional Mayor de San Marcos, Lima [2004].

Kessely Risto y Martti PÄrssinen

2005 "Identidad étnica y muerte: torres funerarias (chullpas) como símbolos de poder étnico en el altiplano boliviano de Pakasa (1250-1600 d. C.) ", Bulletin de l'Institut français d'études andines, 34 (3), pp. 379-410.

LA BARre Weston

1951 "Aymara biologicals and other medicines ", The Journal of American Folklore, 64 (252), pp. 171-178.

La Riva González Palmira

2005 "El zorro mutilado, el zorro despedazado. Reflexiones sobre las representaciones de la fertilidad en los Andes meridionales del Perú », in Antoinette 
Molinié (ed.), Etnografias de Cuzco, Laboratoire d'ethnologie et de sociologie comparative/Centro Bartolomé de las Casas/Instituto Francés de Estudios Andinos, Nanterre/Cuzco, pp. 19-45.

\section{Le BORGNe Yann}

2005 «Evolución del indigenismo en la sociedad peruana. El tratamiento al grupo étnico q'ero ", in Antoinette Molinié (ed.), Etnografias de Cuzco, Laboratoire d'ethnologie et de sociologie comparative/Centro Bartolomé de las Casas/Instituto Francés de Estudios Andinos, Nanterre/Cuzco, pp. 159-179.

\section{Marcoy Paul}

2001 Viaje a través de América del Sur. Del Océano Pacifico al Océano Atlántico, tomo I, Instituto Francés de Estudios Andinos/Pontificia Universidad Católica del Perú/Banco Central de Reserva del Perú/Centro Amazónico de Antropología Aplicada, Lima [1869].

\section{Métraux Alfred}

1931 "Un mundo perdido. La tribu de los Chipayas de Carangas », Sur, 1 (3), pp. 98-131.

1935 "Les Indiens Uro-țipaya de Carangas», Journal de la Société des Américanistes, XXVII (2), pp. 325-415.

MishKin Bernard

1940 "Cosmological ideas among the Indians of the Southern Andes », The Journal of American Folklore, 53 (210), pp. 225-241.

1946 "The contemporary Quechua », in Julian H. Steward (ed.), Handbook of South American Indians, t. II, Smithsonian Institution, Bureau of American Ethnology, Washington, pp. 411-470.

\section{Molinié Antoinette}

2005 «La transfiguración eucarística de un glaciar: una construcción andina del Corpus Christi ", in Antoinette Molinié (ed.), Etnografias de Cuzco, Laboratoire d'ethnologie et de sociologie comparative/Centro Bartolomé de las Casas/Instituto Francés de Estudios Andinos, Nanterre/Cuzco, pp. 69-87.

Molinié Fioravanti Antoinette

1986-1987 «El simbolismo de frontera en los Andes », Revista del Museo Nacional, XLVIII, pp. 251-286.

Morote Best Efraín

2005 "Un nuevo mito de fundación del imperio », in Jorge Flores Ochoa, Juan Núñez del Prado Béjar y Manuel Castillo Farfán (eds), Q'ero, el último ayllu inka. Homenaje a Óscar Núñez del Prado y a la expedición cientifica de la UNSAAC a la nación Q'ero en 1955, Instituto Nacional de Cultura/Universidad Nacional Mayor de San Marcos, Lima, pp. 287-309 [1958].

Mostajo Francisco

1923 "Apuntes etnológicos. Modalidades léxicas, usos y costumbres andinos ", Inca, I (2), pp. 410-420. 
1952 «El carisiri o kari-kjari aimará, el ñacac o ñacaco quechua y el catecate y otros mitos y supersticiones huancaneños ", Perú Indigena, III (7-8), pp. 170-183.

\section{MÜLLER Thomas y Helga MüLLeR}

1984 "Mito de Inkarri-Qollari (cuatro narraciones)", Allpanchis, XX, pp. 125-143.

NORDENSKIöLD Erland

1906 " Travels on the boundaries of Bolivia and Peru », The Geographical Journal, 28 (2), pp. 105-127.

\section{NúÑez del Prado Oscar}

1958 «El hombre y la familia: su matrimonio y organización político-social en Q'ero ", Revista Universitaria, 114, pp. 9-47.

\section{NúÑez del Prado Béjar Juan V.}

1970 «El mundo sobrenatural de los quechuas del sur del Perú a través de la comunidad de Qotobamba », Allpanchis Phuturinqa, II, pp. 57-119.

Platt Tristan

1986 "Mirrors and maize: the concept of yanantin among the Macha of Bolivia ", in John V. Murra, Nathan Wachtel y Jacques Revel (eds), Anthropological history of Andean polities, Maison des Sciences de l'Homme, París/ Cambridge University Press, London, pp. 228-259 [1978].

2001 "El feto agresivo. Parto, formación de la persona y mito-historia en los Andes ", Amuario de Estudios Americanos, LVIII (2), pp. 633-678.

Platt Tristan, Thérèse Bouysse-Cassagne y Olivia Harris

2006 Qaraqara-Charka. Mallku, Inka y Rey en la Provincia de Charcas (14501650). Historia antropológica de una confederación aymara, Instituto Francés de Estudios Andinos/Plural Editores/University of St Andrews/University of London/Inter American Foundation/Fundación Cultural del Banco Central de Bolivia, La Paz.

\section{POSNANSKY Arturo}

1912 Guia general ilustrada para la investigación de los monumentos prehistóricos de Tihuanacué islas del Sol y la Luna (Titicaca y Koaty), con breves apuntes sobre los Chullpas, Urus y escritura antigua de los aborigenes del altiplano andino, Imprenta y Litografía Boliviana, La Paz.

1918 Los chipayas de Carangas, Escuela Tipográfica Salesiana, La Paz.

Renard Casevitz France-Marie, Thierry Saignes y Anne Christine Taylor

$1988 \quad$ Al este de los Andes. Relaciones entre las sociedades amazónicas y andinas entre los siglos XV y xvII, Ediciones Abya-Yala/Instituto Francés de Estudios Andinos, Quito [1986].

Ricard Lanata Xavier

2007 Ladrones de sombra. El universo religioso de los pastores del Ausangate, Instituto Francés de Estudios Andinos/Centro Bartolomé de las Casas, Lima. 
s. d. «El chalay de los pastores de Ch'illka (distrito de Pitumarca, Canchis, Cuzco) [en preparación].

Rivera ANdía Juan Javier

2006 "Mitología en los Andes », in Alejandro Ortiz Rescaniere (ed.), Mitologías Amerindias, Madrid, Trotta, pp. 129-176.

RoBIN Valérie

2005 «Caminos a la otra vida. Ritos funerarios en los Andes peruanos meridionales », in Antoinette Molinié (ed.), Etnografías de Cuzco, Laboratoire d'ethnologie et de sociologie comparative/Centro Bartolomé de las Casas/Instituto Francés de Estudios Andinos, Nanterre/Cuzco, pp. 47-68.

Rowe John H.

1946 "Inca culture at the time of the Spanish conquest », in Julian H. Steward (ed.), Handbook of South American Indians, t. II, Smithsonian Institution, Bureau of American Ethnology, Washington, pp. 183-330.

1956 "Archaeological explorations in Southern Peru, 1954-1955 », American Antiquity, 22 (2), pp. 135-151.

RYDÉN Stig

1947 Archaeological researches in the Highlands of Bolivia, Elanders Boktryckeri Aktiebolag, Göteborg.

SEndón Pablo F.

2004 «El wasi chakuy de Marcapata. Ensayo de interpretación de una costumbre andina », Revista Andina, 39, pp. 51-73.

2009 «Los ayllus de la porción oriental del departamento del Cusco. Aproximación comparativa desde el Collasuyu », Bulletin de l'Institut français d'études andines, 38 (1), pp. 107-130.

Sever Jacques

1921 "Chullpas des environs de Pucara (Bolivie)», Journal de la Société des Américanistes, 13 (1), pp. 55-58.

SQuier E. George

1877 Peru: incidents of the travel and exploration in the land of the Incas, Macmillan and Co., London.

Stobart Henry

2006 Music and the poetics of production in the Bolivian Andes, Ashgate.

Trejo Amador B.

1944 «Los gentiles o ñaupa runacuma », Waman Puma, IV (3), pp. 93-94.

Tsснорік Jr Harry

1946 "The Aymara », in Julian H. Steward (ed.), Handbook of South American Indians, t. II, Smithsonian Institution, Bureau of American Ethnology, Washington, pp. 501-573.

1948 "Aymara texts: Lupaca dialect », International Journal of American Linguistics, 14 (2), pp. 108-114. 
Tschudi Johann Jakob von

2003 El Perú. Esbozos de los viajes realizados entre 1838 y 1842, Pontificia Universidad Católica del Perú, Lima [1846].

Valencia Chacón Américo

1981 «Los chiriguanos de Huancané », Boletín de Lima, 12-13-14, pp. 1-28.

VẢsQuez Emilio

1937 "Sillustani. Una metrópoli pre-incásica », Revista del Museo Nacional, VI (2), pp. 278-290.

Vásquez Emilio, Alfredo Carpio y Daniel E. Velazco

1935 "Informe sobre las ruinas de Tankatanka », Revista del Museo Nacional, IV (2), pp. 240-244.

WACHTEL Nathan

2001 El regreso de los antepasados. Los indios urus de Bolivia, del siglo xx al XVI. Ensayo de historia regresiva, El Colegio de México/Fideicomiso Historia de las Américas-Fondo de Cultura Económica, México [1990].

WiEner Charles

1993 Perú y Bolivia. Relato de viaje. Seguido de estudios arqueológicos y etnográficos y de notas sobre la escritura y los idiomas de las poblaciones indigenas, Instituto Francés de Estudios Andinos/Universidad Nacional Mayor de San Marcos, Lima [1880].

Yamamoto Norio

1981 "Investigación preliminar sobre las actividades agro-pastoriles en el distrito de Marcapata, departamento del Cuzco, Perú ", in Shozo Masuda (ed.), Estudios etnográficos del Perú meridional, Universidad de Tokio, Tokio, pp. 85-137.

ZuIDEMA R. Tom

1973 "Kinship and ancestorcult in three Peruvian communities. Hernández Príncipe's account of 1622 », Bulletin de l'Institut français d'études andines, 2 (1), pp. 16-33.

1990 Inca civilization in Cuzco, University of Texas Press, Austin. 